\title{
BEST WINERY GUIDEBOOK: BENCHMARKING AND ENERGY AND WATER SAVINGS TOOL FOR THE WINE INDUSTRY
}

Prepared For:

California Energy Commission

Public Interest Energy Research Program

Prepared By:

Lawrence Berkeley National Laboratory

Arnold Schwarzenegger

Governor

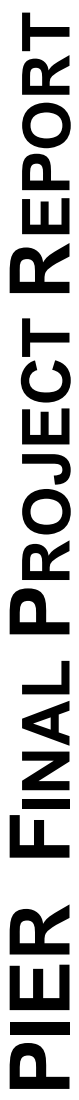

October 2005 


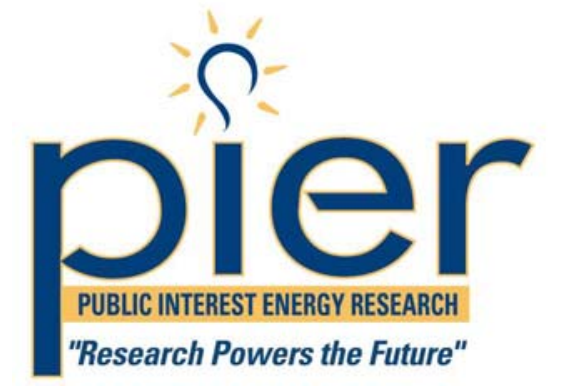

"Research Powers the Future"

\section{Prepared By:}

Lawrence Berkeley National Laboratory

Christina Galitsky, Ernst Worrell and Anthony

Radspeiler

Fetzer Vineyards

Patrick Healy and Susanne Zechiel

Berkeley, CA

Contract No. 500-02-004

Work Authorization No. MR-03-09

Project No. MR-03-09

Prepared For:

\section{California Energy}

Commission

Public Interest Energy Research (PIER) Program

Rajesh Kapoor

Contract Manager

Pramod Kulkarni

Program Area Team Lead

Martha Krebs, Ph. D.

Deputy Director

\section{ENERGY RESEARCH AND DEVELOPMENT}

DIVISION

B.B. Blevins

Executive Director

\section{DISCLAIMER}

This report was prepared as the result of work sponsored by the California Energy Commission. It does not necessarily represent the views of the Energy Commission, its employees or the State of California. The Energy Commission, the State of California, its employees, contractors and subcontractors make no warrant, express or implied, and assume no legal liability for the information in this report; nor does any party represent that the uses of this information will not infringe upon privately owned rights. This report has not been approved or disapproved by the California Energy Commission nor has the California Energy Commission passed upon the accuracy or adequacy of the information in this report. 
LBNL/PUB-3184

\title{
BEST Winery Guidebook: \\ Benchmarking and Energy and Water Savings Tool for the Wine Industry
}

\author{
Christina Galitsky, Ernst Worrell and Anthony Radspieler \\ Lawrence Berkeley National Laboratory \\ Patrick Healy and Susanne Zechiel \\ Fetzer Vineyards
}

\author{
Energy Analysis Department \\ Environmental Energy Technologies Division \\ Ernest Orlando Lawrence Berkeley National Laboratory \\ University of California \\ Berkeley, CA 94720
}

October 2005

This work was supported by the Food Industry Energy Research (FIER) Grant Program of the Public Interest Energy Research Program (PIER) of the California Energy Commission (CEC), by CEC/CIEE Contract MR-0309 through the U.S. Department of Energy Contract under No. DE-AC03-76SF00098. 
DISCLAIMER. The authors of this report and BEST Winery have incorporated the best publicly available information to develop BEST Winery. However, every winery will differ depending on the winemaking practices. This means that energy savings and costs of the measures included in BEST Winery may vary. The BEST Winery results should be interpreted as indications. Only a specialized audit and assessment of the winery may further improve upon the estimates provided by BEST Winery. The California Energy Commission, U.S. Department of Energy, the University of California, Lawrence Berkeley National Laboratory or Fetzer Vineyards, nor any of their employees, makes any warranty, express or implied, or assumes any legal responsibility for the accuracy, completeness, or usefulness of any information contained in BEST Winery. 


\title{
BEST Winery Guidebook:
}

\section{Benchmarking and Energy and Water Savings Tool for the Wine Industry}

\author{
Christina Galitsky, Ernst Worrell and Anthony Radspieler \\ Energy Analysis Department \\ Environmental Energy Technologies Division \\ Ernest Orlando Lawrence Berkeley National Laboratory \\ Patrick Healy and Susanne Zechiel \\ Fetzer Vineyards
}

October 2005

\begin{abstract}
Not all industrial facilities have the staff or the opportunity to perform a detailed audit of their operations. The lack of knowledge of energy efficiency opportunities provides an important barrier to improving efficiency. Benchmarking has demonstrated to help energy users understand energy use and the potential for energy efficiency improvement, reducing the information barrier. In California, the winemaking industry is not only one of the economic pillars of the economy; it is also a large energy consumer, with a considerable potential for energy-efficiency improvement.

Lawrence Berkeley National Laboratory and Fetzer Vineyards developed an integrated benchmarking and self-assessment tool for the California wine industry called "BEST (Benchmarking and Energy and water Savings Tool) Winery. BEST Winery enables a winery to compare its energy efficiency to a best practice winery, accounting for differences in product mix and other characteristics of the winery. The tool enables the user to evaluate the impact of implementing energy and water efficiency measures. The tool facilitates strategic planning of efficiency measures, based on the estimated impact of the measures, their costs and savings.

BEST Winery is available as a software tool in an Excel environment. This report serves as background material, documenting assumptions and information on the included energy and water efficiency measures. It also serves as a user guide for the software package.
\end{abstract}




\section{Table of Contents}

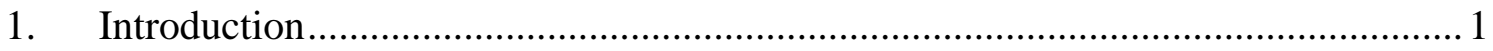

2. The Wine Industry ................................................................................ 3

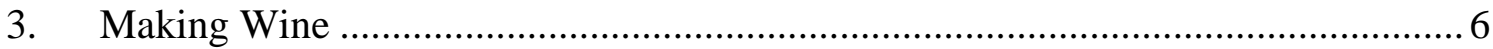

Harvesting the Grapes ...............................................................................................

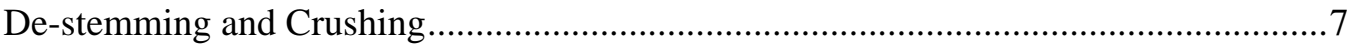

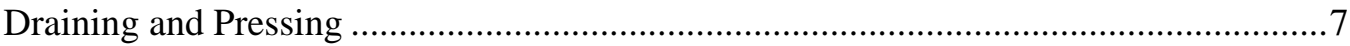

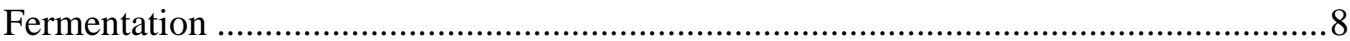

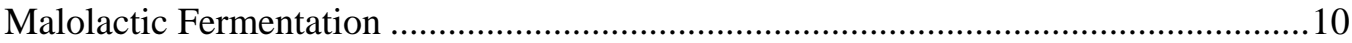

Clarification and Stabilization.................................................................................10

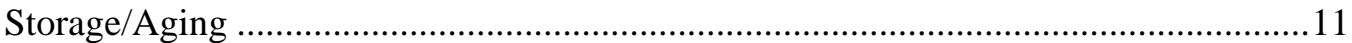

Bottling and Corking ...................................................................................................12

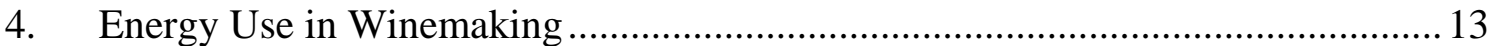

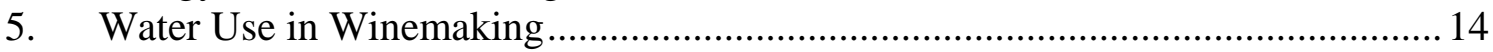

6. Benchmark Modeling - How We Created the "Best” Winery ...................................15

Energy Modeling..........................................................................................................15

Water Modeling ………………………………………………………………. 17

7. Energy Efficiency Opportunities ………………............................................. 18

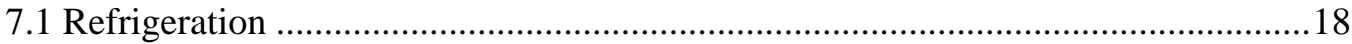

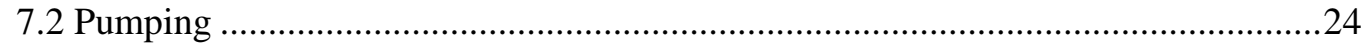

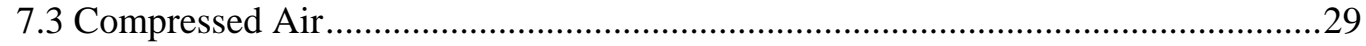

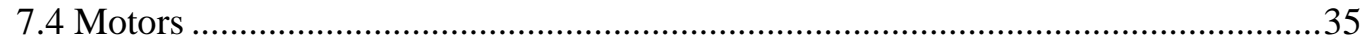

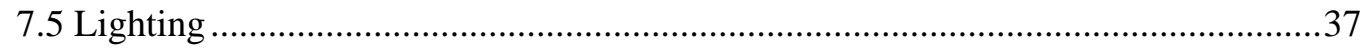

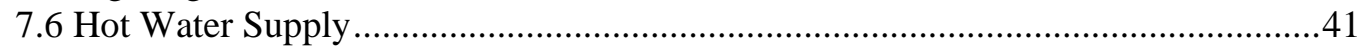

7.7 Other Measures - Fuel ....……………………………………………………45

7.8 Other Measures - Electricity....................................................................................45

7.9 Combined Heat and Power Production (CHP) .........................................................48

8. Water Efficiency Opportunities ............................................................................... 51

8.1 General Water Measures ........................................................................................

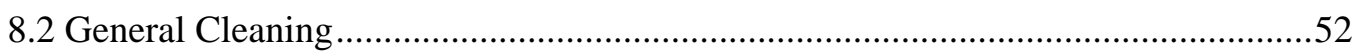

8.3 Barrel Cleaning …………………………………………………………….....

8.4 Cooling Tower ………………………………………………………………....5

8.5 Evaporative Cooling............................................................................................54

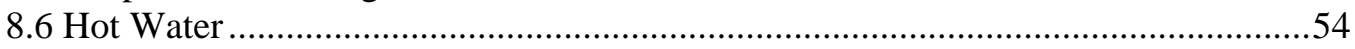

8.7 Humidifiers ……………………………………………………………….

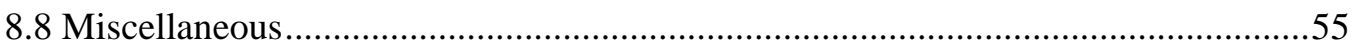

9. Instructions and Tool Documentation...................................................................56

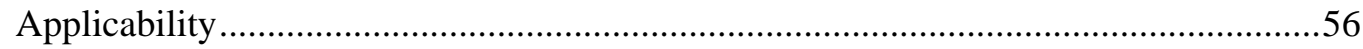

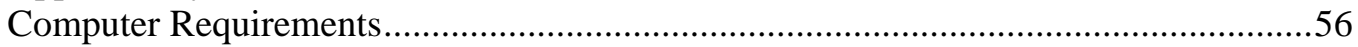

Using BEST Winery - step-by-step ………………………………………………...56

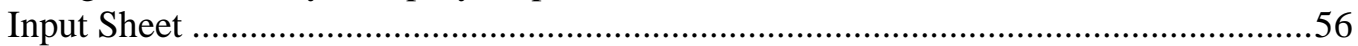

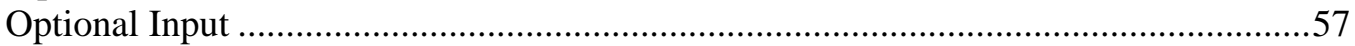

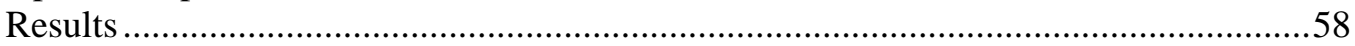

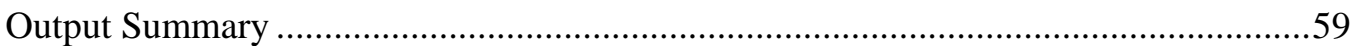

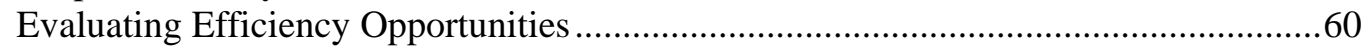

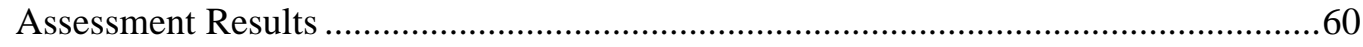

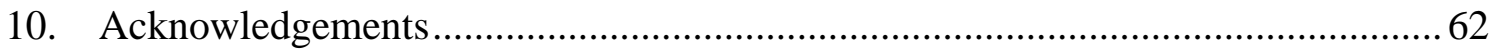

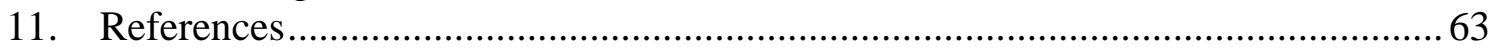




\section{Tables}

Table 1. Regional distribution of wineries in California and of share of grapes crushed.............4

Table 2. Largest varietals in California wine production...........................................................5

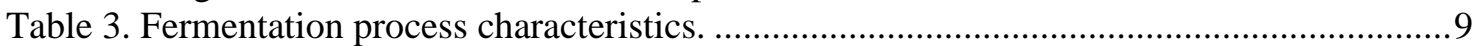

Table 4. Average temperatures in California's main winery regions during fermentation,

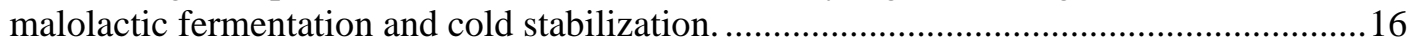

Table 5. Technical and Economic Characteristics of small-scale cogeneration technologies ....49

\section{Figures}

Figure 1. Shipments of wine in California from 1959 to 2002 and production of wine in

California from 1995 to 2000 . .3

Figure 2. Simplified Schematic Presentation of the Winemaking Process .................................6

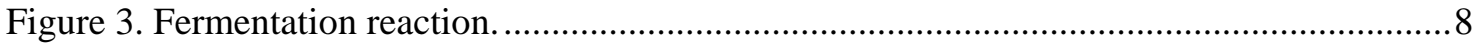




\section{Introduction}

California has over 1100 wineries that produce over 500 million gallons of wine per year, contributing about $\$ 33$ billion to the Californian economy (directly and indirectly). California makes most of the total wine in the U.S.; in 2000, California generated 565 million gallons of wine, representing almost $92 \%$ of all U.S. production.

The California winemaking industry consumes over $400 \mathrm{GWh}$ of electricity annually, the second largest electricity-consuming food industry in California after fruit and vegetable processing (e.g. canning). Besides electricity, the industry also consumes considerable amounts of fuel, including natural gas, LPG and propane.

Much of the electricity used in winemaking goes to refrigeration for cooling and cold storage. The rest is mainly used for compressed air, hot water or electricity for pumping and bottling line motors, though compressed air demand is highly variable from winery to winery. Enclosed areas for storage and processes also require lighting and many of these areas are cooled. Other non-process use power is required for buildings and other miscellaneous administrative or maintenance applications. Hot water is needed for cleaning barrels and equipment and for heating red wine ferments and yeast generator tanks.

The major water use areas are fermentation tanks, barrel washing, barrel soaking, bottling lines, cellars, and the crush pad. In efforts to conserve water, many wineries have begun to use treated wastewater to irrigate vineyards or landscaping, or may use it for frost protection, fire protection or dust abatement. Water use and disposal require pumping and heating which also increases energy costs.

Energy and water costs have increased rapidly for wineries located in California, making energy and water efficiency improvement an essential part of the business. Furthermore, excessive energy and water use result in considerable environmental damage. As a result, California winemakers have begun to implement various efficiency measures. Our experience shows winemakers have started to implement sustainable practices in viniculture and their wineries more than any other industry with whom we have worked.

Benchmarking can be a useful tool for understanding energy and water consumption patterns in an industrial facility and for designing policy to improve energy efficiency. Energy or water benchmarking for industry is a process in which the energy or water performance of an individual plant or an entire sector of similar plants is compared against a common metric that represents "standard" or "optimal” performance. It may also entail comparing the energy (or water) performance of a number of plants to each other. Because benchmark evaluation tools are used for comparison across a number of plants, there are two important characteristics they should have. First, because they are applied to plants or sectors of different sizes and outputs, the metric used should be irrespective of plant size. This is accomplished using intensity, which, for energy, 
measures energy use per unit of output. However, deciding how to measure units of output is not always clear. Second, the tool should be applicable to a wide range of facilities (in order to increase the robustness of the analysis) and, therefore, should be able to compensate for differences in production (such as tons of grapes received) at similar facilities.

While benchmarking provides insights into the relative energy and water performance of the plant, it is also a good starting point for analysis of additional improvement opportunities.

In designing an evaluation tool that compensates for production differences, it is necessary to take a look inside the production processes and account for the various process steps used. BEST Winery is based on this type of a process-step benchmarking approach. In this approach, the key process steps are identified and a benchmark performance is assigned to each step ${ }^{1}$. The performance of your winery is then compared to a best or optimal winery, incorporating information about how each step is used by the winery. The performance of the winery is calculated and expressed as an Energy Intensity Index (EII) and a Water Intensity Index (WII). EII and WII are expressed relative to the benchmark.

BEST Winery also allows the user to preliminarily evaluate opportunities for energy and water efficiency improvement, to assess the impact on the performance of the facility, and to evaluate operation costs. This can help the user in developing a preliminary implementation plan for energy and water efficiency improvement.

This report describes the BEST Winery benchmarking and assessment tool. The report starts with a description of the industry, followed by a discussion of the winemaking process. This is followed by an analysis of energy and water use in a typical winery. We discuss the energy and water efficiency measures that are included in the BEST Winery tool. The report also serves as manual to the tool. Sections 6 and 9 contain user instructions. BEST Winery is available as an Excel tool that can be run on any PC operating Windows 2000 or higher.

The BEST Winery tool has been developed by Lawrence Berkeley National Laboratory (LBNL) and Fetzer Vineyards, with financial support of the California Energy Commission (CEC). LBNL is a research laboratory of the U.S. Department of Energy managed by the University of California. LBNL develops tools and studies to reduce the environmental impact of energy use. Fetzer Vineyards in Hopland is one of the leading winemakers in the field of sustainable winemaking. Fetzer has pioneered the use of organic agricultural practices and renewable energy use in the wine industry.

\footnotetext{
${ }^{1}$ In the case of BEST Winery, the benchmark is based on best commercially available technology for each process step.
} 


\section{The Wine Industry}

California has over 1100 wineries $^{2}$ that produce over 500 million gallons of wine per year, contributing about $\$ 33$ billion to the Californian economy (directly and indirectly). California makes most of the total wine in the U.S.; in 2000, California generated 565 million gallons of wine, representing almost $92 \%$ of all U.S. production. The U.S. is the fourth largest wine producer in the world, after France, Italy and Spain. Wine production in California has tripled over the past four decades (see Figure 1). In recent years, global overproduction and low-cost imports from areas like Australia have put pressure on wine producers in California.

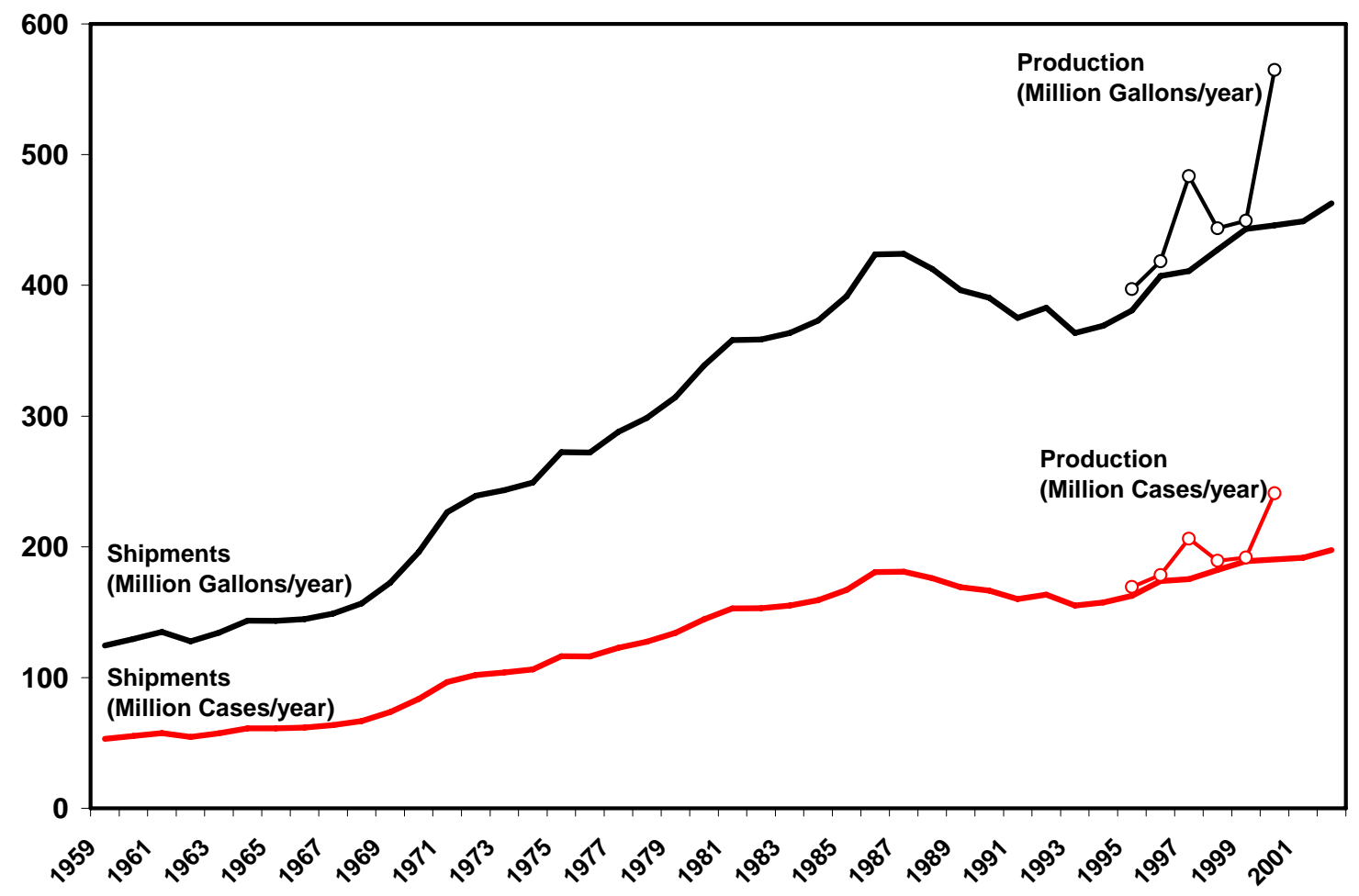

Figure 1. Shipments of wine in California from 1959 to 2002 and production of wine in California from 1995 to 2000. Shipments are generally smaller than production due to stock changes and losses, but follow the same trend as production. Source: The Wine Institute, 2002 and 2004.

Wine production is concentrated in a few areas, most notably in Northern California. Table 1 provides a distribution of the number of wineries within 10 regions in California. Although the largest number of wineries are located in the Napa and Sonoma regions, production is concentrated in the Central Valley where very large wineries produce low-cost wines. Most notable are the large Central Valley wineries operated by Michael Hat and E. and J. Gallo. In California, there are a very large

\footnotetext{
${ }^{2}$ The website http://www.cawinemall.com/local.html provides a listing of all wineries in California.
} 
number of small wineries that produce less than 20,000 cases per year, but also a few wineries that produce over 1 million cases per year. These differences in distribution of wineries and of grapes processed (i.e., winery capacity) are illustrated in Table 1 . While almost 32\% of all wineries are located in Napa, they crush only about $4 \%$ of all grapes. In the Central Valley $76 \%$ of all grapes are crushed, but only $5 \%$ of the wineries are located in the region.

Table 1. Regional distribution of wineries in California and of share of grapes crushed. Source: Wine Institute, 2004, California Wineries Mall, 2004.

\begin{tabular}{|c|c|c|c|c|c|}
\hline Region & $\begin{array}{l}\text { Share of } \\
\text { grapes } \\
\text { processed }\end{array}$ & $\begin{array}{l}\text { Number } \\
\text { of } \\
\text { Wineries }\end{array}$ & $\begin{array}{l}\text { Share of } \\
\text { wineries }\end{array}$ & Main locations & $\begin{array}{l}\text { Number of } \\
\text { Wineries }\end{array}$ \\
\hline Central Coast & $5.2 \%$ & 32 & $2.9 \%$ & Carmel Valley & 8 \\
\hline Central Valley & $76.1 \%$ & 58 & $5.3 \%$ & Lodi & 12 \\
\hline \multirow{2}{*}{$\begin{array}{l}\text { Foothills (Sierra } \\
\text { Nevada) }\end{array}$} & \multirow[t]{2}{*}{$0.5 \%$} & \multirow[t]{2}{*}{68} & \multirow[t]{2}{*}{$6.2 \%$} & Plymouth & 15 \\
\hline & & & & Placerville & 8 \\
\hline \multirow{3}{*}{$\begin{array}{l}\text { Mendocino/Lake } \\
\text { District }\end{array}$} & \multirow[t]{3}{*}{$2.7 \%$} & \multirow[t]{3}{*}{55} & \multirow[t]{3}{*}{$5.0 \%$} & Hopland & 9 \\
\hline & & & & Philo & 15 \\
\hline & & & & Ukiah & 11 \\
\hline \multirow[t]{3}{*}{ Napa } & \multirow[t]{3}{*}{$4.2 \%$} & \multirow[t]{3}{*}{350} & \multirow[t]{3}{*}{$31.8 \%$} & Calistoga & 45 \\
\hline & & & & Napa & 116 \\
\hline & & & & St. Helena & 108 \\
\hline \multirow[t]{3}{*}{ Sonoma } & \multirow[t]{3}{*}{$5.9 \%$} & \multirow[t]{3}{*}{237} & \multirow[t]{3}{*}{$21.5 \%$} & Healdsburg & 85 \\
\hline & & & & Santa Rosa & 26 \\
\hline & & & & Sonoma & 30 \\
\hline San Francisco Bay & $0.7 \%$ & 116 & $10.5 \%$ & Livermore & 20 \\
\hline South Coast & $4.5 \%$ & 149 & $13.5 \%$ & Paso Robles & 48 \\
\hline South California & $0.1 \%$ & 37 & $3.4 \%$ & Temecula & 16 \\
\hline Total & $100 \%$ & 1102 & $100 \%$ & & \\
\hline
\end{tabular}

There is an increasing concentration of ownership by a number of large wine and beverage corporations in the wine industry. Among the largest are Canandaigua Wine, E. and J. Gallo Winery, Brown-Forman Corporation and a few others.

Most wineries produce a number of different wines. In California, wineries produce about 23 varietals of red wines, and 21 varietals of white wine, in addition to dessert and sparkling wines. However, a small number of the varietals represent the majority of wines produced in California. The most produced red wines are Cabernet Sauvignon, Merlot, Zinfandel, and Syrah, while the most produced white wines are Chardonnay, Colombard, and Sauvignon Blanc. Table 2 provides a breakdown of the varietals processed, by tons of grapes crushed in the 2002 harvest. 
Table 2. Largest varietals in California wine production. Source: Wine Institute, 2002, 2004.

\begin{tabular}{|l|r|r|}
\hline Variety & $\begin{array}{l}\text { 2002 Production } \\
\text { (tons crushed) }\end{array}$ & $\begin{array}{l}\text { Share of total } \\
\text { (\% by red or white) }\end{array}$ \\
\hline Red & $\mathbf{1 , 8 1 6 , 7 1 6}$ & $20.9 \%$ \\
\hline Cabernet Sauvignon & 379,183 & $20.4 \%$ \\
\hline Zinfandel & 369,772 & $16.9 \%$ \\
\hline Merlot & 306,992 & $10.1 \%$ \\
\hline Rubired & 183,457 & $5.6 \%$ \\
\hline Syrah/Shiraz & 101,538 & $46.2 \%$ \\
\hline White & $\mathbf{1 , 2 8 7 , 8 6 5}$ & $24.3 \%$ \\
\hline Chardonnay & 594,905 & $9.2 \%$ \\
\hline French Colombard & 312,937 & $6.0 \%$ \\
\hline Chenin Blanc & 117,875 & $3.9 \%$ \\
\hline Sauvignon Blanc & 76,587 & \\
\hline Burger & 50,386 & \\
\hline
\end{tabular}




\section{Making Wine}

There are numerous variations in the way the grapes are processed. The variations are driven by the type of grapes (varietals) processed and wine produced, the sugar content of the grapes, product characteristics as specified by the winemaker, the lay-out of the winery, as well as conditions during the harvesting period. In the process description we focus on energy and water use, and the implications of process variables on energy and water use. For a more detailed description of the process and the impact on wine quality we refer to Boulton et al. (1996). Figure 2 shows a simple schematic of the process of making wine.

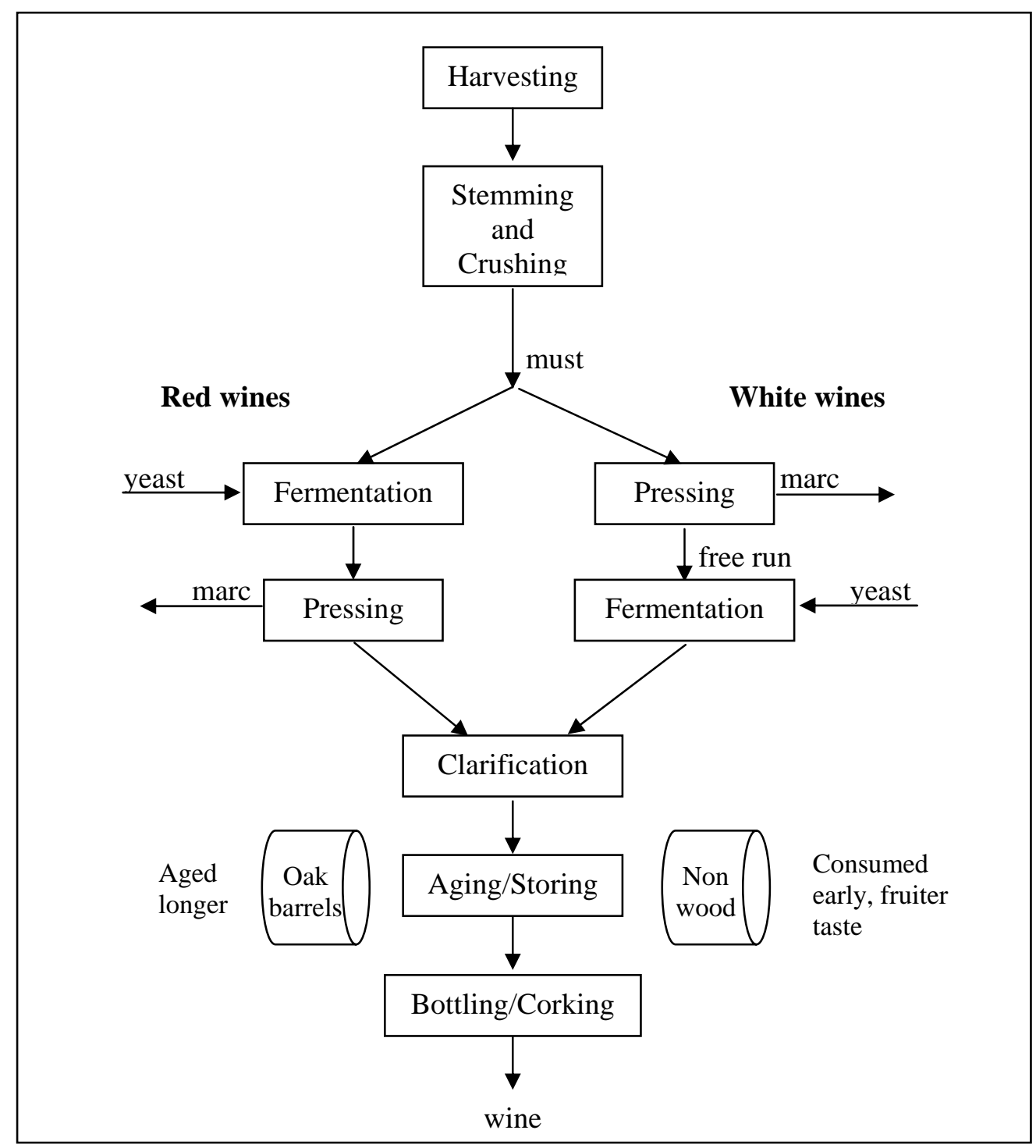

Figure 2. Simplified Schematic Presentation of the Winemaking Process 


\section{Harvesting the Grapes}

The fruit are allowed to stay on the vines until fully ripe. Error should be on the side of leaving the fruit on the vines too long (Boulton et al. 1996). A slight frost will not injure the grapes for winemaking, but rather will improve the final product. Gathering grapes in damp weather or when dew is on them is avoided. All unripe and bad berries are removed at this stage. The grapes are transported to the winery by truck.

\section{De-stemming and Crushing}

At the winery, the grapes are received at a receiving bin or station. Often the sugar content is measured at random in the incoming bins, as this value is important to control the fermentation process. The bins are emptied into the receiving station with a crane. To prevent damaging the grapes, the grapes are moved with different means, most often a combination of screw conveyors or pumps. A small amount of water is used to empty the incoming bins. After reception, the stems are removed from the grape berries. The mixture of juice, skins, seeds and pulp produced from the de-stemming and crushing processes is called must. Small, fragmented pieces of stems that get into the must will increase the wine's stringency or bitterness and their inclusion should be avoided as much as possible. The skins and pulp are then broken to free the juice. The goal of crushing is to free the juice without squashing the seeds.

Some wineries may receive part of or all of the grapes as juice, in which case, destemming and crushing of the grapes have been done elsewhere. Also, some wineries are moving toward de-stemming and crushing in a mobile unit at the vineyard, making it easier to distribute the stems directly around the vineyard instead of returning them later (or simply disposing them).

There are special conditions and wine styles that require and utilize a different crushing sequence or the partial use of whole berries. However, for the vast majority of wines are processed using the above described sequence.

Depending on the temperature of the grapes at time of delivery and the need for skin contact (for white wine only) the must may need to be cooled. If cooling is needed the must line should be kept as short as possible or be insulated to reduce heat transfer to the must. The must is pumped to fermenting tanks or to the pressing stage. The must may be covered by carbon dioxide to reduce oxidation.

\section{Draining and Pressing}

The must can be drained in vertical tank with filters in the bottom. The must is pumped into the vertical tank, and the juice is allowed to drain through the filters. However, if the juice is not naturally drained, a press may be used to extract the juice. In many (larger) wineries a press will be the main way to extract the juice from the must. Both the speed and the pressure of the press affect the quality of the wine. A membrane press provides a wine quality that is comparable to that of draining, as the juice is lower in tannins and suspended solids. Hence, the membrane press is generally the preferred pressing technology. The membrane press uses a motor, while pumps and compressors 
are used to pump must and juice. Water is used to clean the press at the end of the day, or in between changes of red and white wines.

For red wine, after crushing, the must goes directly to the fermentation stage and pressing is done after fermentation. The skins give the wine its color; so leaving the skins, seeds and pulp in until after fermentation gives the wine a red, rather than clear color.

For white wine, however, skins, seeds and pulp are separated from the juice after crushing. This juice is called free-run. The remaining skins, seeds and pulp are called the marc. Sometimes the marc is pressed first with a modern bladder-type cylindrical press and then with a traditional basket press. Then the marc is discarded. One ton of grapes will yield 155 to 195 gallons of must, with 120 to 160 gallons being free-run juice. The leftover cake (pomace) is often recycled within the vineyard. The pomace is removed with screw conveyors to waiting trucks.

After pressing and before fermentation, the sugar and acidity of the juice is determined. Sulfur dioxide $\left(\mathrm{SO}_{2}\right)$ is usually added in small amounts to inhibit wild yeast and bacterial growth and to prevent oxidation. Yeast starter cultures and possibly clarifying agents are added to facilitate a clean and consistent fermentation.

\section{Fermentation}

Fermentation is an extremely important step in the winemaking process, determining taste and quality. Control of this process is important to warrant the quality of the wine. In the fermentation stage, yeasts convert the sugars to alcohol and carbon dioxide. This reaction is shown in Figure 3. The alcohol produced through fermentation is the wine's major flavor component. It also affects the solubility of many wine constituents and enhances the wine's resistance to spoilage. Fermenting is mostly done in stainless steel tanks. However, certain wines are fermented in the barrel. Of the more common wines only Chardonnay is barrel fermented.

$$
\mathrm{C}_{6} \mathrm{H}_{12} \mathrm{O}_{6} \stackrel{\text { yeast }}{\longrightarrow} 2 \mathrm{CH}_{3} \mathrm{CH}_{2} \mathrm{OH}+2 \mathrm{CO}_{2}+\text { heat }
$$

Figure 3. Fermentation reaction.

The fermentation process takes place at a controlled temperature for quality purposes, to which the wine needs to be cooled at the beginning of fermentation and throughout the process. The fermentation reaction also generates heat (as shown in Figure 3) that needs to be removed during fermentation. Cooling of the fermentation tanks and barrel room (where some of the white wines are fermented) is one of the major energy uses in a winery. The length of the fermentation period depends on the sugar content of the grapes and juice, and is controlled by the winemaker to optimize the quality of the wine.

The fermenting tanks are filled to about five to six inches from the top to avoid foaming-over during fermentation. Fermentation is performed in barrels or in tanks, depending on the type of wine produced. For red wines, the juice of the must is 
fermented on the skins with the seeds and pulp, whereas for white wine, the skins, seeds and pulp have already been removed in the pressing stage and only the free run is fermented. Table 3 gives the typical parameters for the main processing routes of wines.

Table 3. Fermentation process characteristics. Sources: Fetzer, 2004; Boulton et al., 1996.

\begin{tabular}{|l|c|c|c|}
\hline Wine & $\begin{array}{c}\text { Typical Sugar } \\
\text { Content } \\
\left({ }^{\circ} \text { Brix) }\right.\end{array}$ & $\begin{array}{c}\text { Typical Fermentation } \\
\text { Temperature } \\
\left({ }^{\circ} \text { F) }\right.\end{array}$ & $\begin{array}{c}\text { Typical Fermentation } \\
\text { Period } \\
\text { (days) }\end{array}$ \\
\hline Red & $22-26$ & $75-80$ & $7-10$ \\
\hline $\begin{array}{l}\text { White - tank } \\
\text { fermented sweet }\end{array}$ & $21-22$ & $48-50$ & 28 \\
\hline $\begin{array}{l}\text { White - tank } \\
\text { fermented dry }\end{array}$ & $23-24$ & $58-60$ & 14 \\
\hline $\begin{array}{l}\text { White - Barrel } \\
\text { fermented }\end{array}$ & $23-24$ & 60 & 7 \\
\hline
\end{tabular}

For red wine, the must is fermented for seven to ten days at a temperature between 75 and $80^{\circ} \mathrm{F}$ (24 to $27^{\circ} \mathrm{C}$ ). During this period, color is extracted from the skins. The skins and solids in the must will float to the top of the fermenter, forming a cake from which the carbon dioxide cannot escape and only a layer of juice contacts the skins. This cake is broken down by punching down the cake by hand, by pumping over the juice to the top of the cake using a must pump, or by stirring via mechanical means, including rototanks that turn the entire contents over like a cement mixer.

White wines are fermented at cooler temperatures than reds to achieve the best quality. For white wines, fermentation takes two to forty-five days at a temperature usually between 45 and $65^{\circ} \mathrm{F}$ ( 7 to $18^{\circ} \mathrm{C}$ ). The lower the temperature, the longer the fermentation continues and the more fruitiness results in the wine. Fermenters allowed to get too hot produce off flavors and can get stuck. Hence, temperature control is important.

Fermentation can continue until the wine is dry (without residual sugar) or be stopped before completion by killing or removing the yeast. This yields some level of sweetness, ranging from a hint to very sweet. This stoppage can be done by adding alcohol to $15 \%$ or more as in ports or Sherries, by adding $\mathrm{SO}_{2}$ or sorbic acid, by chilling the must (or free run) and filtering out the yeast cells or simply by filtering or centrifuging out the yeast cells.

Stainless steel tanks or oak barrels are the most common fermentation vessels. Stainless steel equipment has three major advantages over other types of equipment. Firstly, it neither imparts nor removes any flavors in the wine. Secondly, it is easily fitted with temperature controls, including jackets to circulate refrigerant, thermostats, internal stirring components and computerized controls that can maintain the temperature of the 
must within one or two degrees. Third, it does not provide a medium for bacterial growth and can be easily cleaned and sterilized.

\section{Malolactic Fermentation}

Malolactic fermentation or conversion refers to the conversion of malic acid in the wine to lactic acid. It is typically used to reduce the acidity of wines made from grapes grown in colder climates. However, it is also applied in many Californian wineries. Some wines have an autonomous malolactic fermentation if kept at a suitable temperature (that does not inhibit the fermentation), i.e. red wines. Most of the red wines in California undergo malolactic fermentation. The share of red wine varies from winery to winery. Malolactic fermentation in red wines is done in the tank, which is heated to provide for the reaction.

In other wines, e.g. Chardonnay, the malolactic fermentation is started by leaving the wine on the yeast lees and heating the barrels to a sufficiently high temperature to have the fermentation reaction proceed. The lees are the dirt, dust, cellulose, dead yeast cells, bacteria, tartrates and pectin that are discarded during racking (see below). The temperature of the wine should not exceed $64-65^{\circ} \mathrm{F}$. The room with the barrels is heated to approximately $70^{\circ} \mathrm{F}$ (as the wooden barrels insulate the wine) for a period of 1 to 3 months, after which they are cooled and stored at $58-60^{\circ} \mathrm{F}$. The barrels are moved and topped every other week, and again once per month if the wine is treated with $\mathrm{SO}_{2}$.

\section{Clarification and Stabilization}

Clarification can be done either before, during, or after aging. Clarifying wine separates the clear wine from the spent yeasts and other solids after fermentation. Yeasts are sometimes left in the wine to add complexity. Stabilization is needed to remove the tartaric acid. In California, the most common techniques to clarify wine are racking, cold stabilization, fining and filtering. Often a combination is used. A new technique developed in Europe, and being demonstrated in California, is electro-dialysis.

Racking is the oldest technique of clarification. It involves simply siphoning off the relatively clear wine after the lees have settled to the bottom. Some wineries rack once, others rack more than once. Frequent racking can injure the aroma of the wine and render it liable to become acidic. Because the $\mathrm{SO}_{2}$ content initially added is exhausted during fermentation, it is adjusted again at this stage to prevent spoilage and oxidation.

Cold Stabilization is generally used as an enhancement to racking. It removes excess tartaric acid that may form potassium bitartrate crystals that can show up in wine bottles or on corks. Although they dissolve easily and are edible and harmless, they are generally unacceptable to buyers. The process of cold stabilization allows the wine to warm up to room temperature and then chills it down to about 25 to $32^{\circ} \mathrm{F}\left(-4\right.$ to $\left.0^{\circ} \mathrm{C}\right)$. The tartaric acid crystallizes and is drawn off by racking.

Fining begins by stirring a fining agent into the wine that is heavier than both water and alcohol and does not dissolve in either. The agent settles to the bottle of the vessel causing small, suspended particles to precipitate out with it. The clarified wine is then 
separated by racking off the lees. Physical fining agents absorb tiny particles and drag them. Chemical fining agents form chemical bonds with hydrogen elements in the particles. Fining agents include proteins, earths, synthetic polymers, colloids, activated carbon, silica suspensions, and copper sulfate. Over-fining should be avoided as it can result in thin wines that lack aroma complexity, flavor depth, viscosity and aging potential. Passing the wine through various filters allows great flexibility to winemakers than one or no filters; however, it can also remove flavor or aroma elements.

Depth or sheet filtration uses a thick layer of fine material (such as diatomaceous earth) to trap and remove small particles. Surface or membrane filtration passes wine through a thin film of plastic polymer with uniformly sized holes that are smaller than the particles. Sterile filtration uses micropore filters that are fine enough to remove yeast cells to prevent further fermentation.

Electrodialysis is a membrane process driven by an electric current, moving the tartrate ions from the wine through a membrane to an aqueous solution. This technology has been developed in Europe and is applied in wineries around the world, and is currently being demonstrated at wineries in California. Test wineries have found that this technology uses much less energy than cold stabilization (Fetzer, 2004).

\section{Storage/Aging}

After clarification, the wine is stored and aged. Wine is stored at the winery or an offsite warehouse year round, in order to supply wine year round. Storing requires capital and operational expenditures for racking, topping and maintenance of the appropriate temperature. The temperature controls the chemical reactions taking place in the wine that affect the quality of the wine. The program of aging followed by a winery depends on the type of wine, the style, and price category, and will vary by winery and wine type. In most wineries in California, the cellar is a warehouse in which the temperature and humidity is controlled. Temperature control is achieved using cool night air or artificial cooling that supplements the nighttime air at periods of high temperature. In smaller wineries, the cellar may actually be underground (reducing cooling needs). In the very large wineries found in the Central Valley, generally lowcost wines are produced and storage is kept to a minimum. In these wineries storage may take place in outdoor (sometimes insulated) tanks.

Wine should be aged under cool conditions, generally 52 to $55^{\circ} \mathrm{F}$ (11 to $13^{\circ} \mathrm{C}$ ) or cooler and not more than $60^{\circ} \mathrm{F}\left(16^{\circ} \mathrm{C}\right)$. In California, white wines stored in tanks are generally kept at 40 go $44^{\circ} \mathrm{F}\left(4\right.$ to $7^{\circ} \mathrm{C}$ ) on average. White wines are typically made without wood aging and are consumed when they are relatively young, thus retaining fresh and fruity aromas and flavors. Only Chardonnay is kept in barrels, while the others are stored in tanks. This adds to the taste and quality of the Chardonnay. Chardonnay may age between 0 and 6 months in the barrel, and is stored in a room cooled to about 58 to $60^{\circ} \mathrm{F}\left(14\right.$ to $\left.16^{\circ} \mathrm{C}\right)$. 
Red wines generally gain quality and complexity by aging in oak barrels. The oak imparts a vanilla, toast taste. Red wines are generally stored between $45^{\circ} \mathrm{F}\left(7^{\circ} \mathrm{C}\right)$ and $70^{\circ} \mathrm{F}\left(21^{\circ} \mathrm{C}\right)$, or on average $59^{\circ} \mathrm{F}\left(15^{\circ} \mathrm{C}\right)$. Red wines may age up to six months for light red wines and up to 3 years for robust red wines in the barrel.

Wine is racked every two to three months while aging. As wine ages, typically $2-5 \%$ by volume per year (on average 3\%) of the wine is lost due to evaporation or ullage. The lost wine is replaced to avoid oxidation and to prevent growth of vinegar bacteria, which develops in the presence of air in warm conditions. Barrels are topped with wine at least every two weeks. Pumps and forklifts are used to transport and top the barrels. In addition, barrels are washed and cleaned to remove tartrates and other remains in the barrels. Washing and cleaning is mainly done with water. The application of ozone reduces the water demand for barrel cleaning.

\section{Bottling and Corking}

Bottling is the final step in winemaking. Some wineries have a bottling facility in house, while others outsource the work to other wineries or bottling facilities. Still others (mainly small wineries) use a mobile bottling facility. Even bottling is important to wine quality as the wine continues to age while in the bottle after bottling has been completed.

Wine is pumped to tanks at the bottling facility. Nitrogen can be used to fill the headspace in a tank to reduce oxidation. Prior to bottling, the wine is filtered to remove any solids remaining in the wine after aging. For wines that have not gone through a malolactic fermentation process, the wine is filtered through a membrane, to make sure that no biological or bacterial activity takes place in the wine when in the bottle.

The bottling line is generally contained in its own separate room, and is kept dust free and under a slightly positive air pressure to reduce the growth of organisms and reduce contamination of the wine. Fine clear weather is the best time for bottling all wines. All bottles must be clean and dry. Bottles are cleaned and dedusted by blowing compressed air into the bottle. Bottling equipment varies from simple siphon hoses, funnels, hand corking and labeling machines to very modern and completely automated bottling lines. Corks must fill up the neck of the bottle to render them airtight, with a small space in the neck of the bottle between the wine and the cork. Bottles are stored in a cool cellar on their sides. To reduce the rate of oxidation and chemical reactions a low storage temperature is preferred, although temperatures may increase during transportation. 


\section{Energy Use in Winemaking}

Based on utility data, we estimate that the California winemaking industry consumes over $400 \mathrm{GWh}$ of electricity per year, making it the second largest electricityconsuming food industry in California after the canned fruit and vegetables industry. Besides electricity, the industry also consumes considerable amounts of fuel, including natural gas, LPG and propane.

Much of the electricity used in winemaking goes to refrigeration for fermentation cooling, cold stabilization and cold storage. The rest is mainly used for compressed air, hot water or electricity for pumping and bottling line motors, though compressed air demand is highly variable from winery to winery. Enclosed areas for storage and processes also require lighting and many are cooled. The biggest use of compressed air is in the presses for which the compressor must have sufficient capacity to charge the air receiver so it is ready for each pressing cycle. However, presses are only used about 1,200 hours or less per year. Hot water is needed for cleaning barrels and equipment and for heating red wine ferments and yeast generator tanks. Other non-process use power is required for buildings and other miscellaneous administrative or maintenance applications.

Specific energy use will vary for each winery, as will the distribution of energy use, depending on the type of products made, process choices, and efficiency of the operation. Chapter 6 will document the typical energy use in an energy efficient winery. 


\section{Water Use in Winemaking}

The main use of water within the winery itself (excluding vineyards) is for cleaning. The major water use areas are the crush pad and press area, the fermentation tanks (both primary and malolactic fermentation), barrel washing, barrel soaking, the bottling line, and the cellars and barrel storage areas. Water is used to wash down floors and areas throughout the winery, to clean the equipment including the receiving lines, the presses, the tanks, and the bottling lines, and to wash the barrels at various stages of the winemaking process. Water is also used for humidification in the cellars and barrel storage areas, and other non-production uses at the winery, like toilets and sinks in office buildings and maintenance workshops.

Some wineries treat their own wastewater, while others send it to a municipal treatment plant. Many wineries have begun to use treated wastewater to irrigate vineyards or landscaping, or may use it for frost protection, fire protection or dust abatement.

In addition to increased costs for water, the more water that is used, the higher the costs are for wastewater disposal and for the energy required for water pumping and/or heating. 


\section{Benchmark Modeling - How We Created the "Best" Winery}

In BEST Winery, the benchmark winery is based on all commercially available efficiency technologies used anywhere in the world. No actual winery with every single efficiency measure included in the benchmark will likely exist; however, the benchmark sets a reasonable standard by which to compare. The energy and water consumption of the benchmark facility will differ due to differences in processing at a given winery. BEST Winery accounts for these variables and allows the user to adapt the model to operational variables specific for his/her winery.

In order to model the benchmark, i.e., the most energy and water efficient winery, so that it represents a facility similar to the user's winery, we first require the user to input production variables in the input sheet (see instructions in Section 9 for more information on how to input variables). These variables allow BEST Winery to estimate a benchmark winery that is similar to the user's winery, giving a better picture of the potential for that particular facility, rather than benchmarking against a generic winery. The production variables required in BEST Winery include the amount of grapes received annually, the amount of juice received annually, the juice that is fermented annually, the amount of wine that undergoes malolactic fermentation, the amount of wine that is cold stabilized, the amount of wine that is stored per year (or, in any given twelve month period), the wine produced by the plant per year and the wine that is bottled per year. Each of these must be input for each of the four categories of wine in the model: red wines, sweet white wines, dry wines that are tank fermented and dry wines that are barrel fermented. These variables will affect both the energy and water used at a benchmark winery similar in characteristics to the user's winery.

\section{Energy Modeling}

We have modeled the energy use at a winery as seven main process steps:
1. Receiving,
2. Pressing,
3. Fermentation,
4. Malolactic Fermentation,
5. Clarification \& Stabilization and Electrodialysis,
6. Aging \& Storage, and
7. Bottling.

In addition, we have separately calculated energy requirements for pumping and for additional miscellaneous uses, such as lighting, office equipment, water heating, space heating, and forklift operation.

For the receiving and pressing stages, energy use is based on an estimated average crush season length and the amount of time that the equipment runs per day. Though we used default values for the benchmark winery, these values are located in the 
optional input sheet, and can be used as is or changed by the user to model more closely the operational characteristics of the individual winery.

For fermentation, the main variables affecting energy use are ambient temperature, the temperature of the incoming juice and the sugar content of the juice. Table 4 shows the average temperatures for California's main winery regions during fermentation, as well as malolactic fermentation and cold stabilization. On the input sheet in BEST Winery, we ask the user to choose the region where their winery is located, as well as the main region from which their grapes come. We link these locations to the database included in BEST Winery (see Table 4) for temperature data that is used to calculate energy requirements during fermentation. Other variables that affect fermentation energy use are fermentation temperature, fermentation time, sugar content of the incoming grapes, building size, and vessel size. Based partly on the production variables input by the user, BEST Winery estimates the building and vessel size. These, along with fermentation temperature, fermentation time and sugar content of the incoming grapes, are estimated as default values in BEST Winery. As with all default values in BEST Winery, the user has the option to change these default values on the optional input sheet for maximum flexibility. If default values are not changed, they are estimated by BEST Winery based on data we received from wineries and vendors to the wine industry.

Table 4. Average temperatures in California's main winery regions during fermentation, malolactic fermentation and cold stabilization. Source: NOAA, 2004.

\begin{tabular}{|l|c|c|c|}
\hline Area & $\begin{array}{c}\text { Fermentatior } \\
\text { Ambient }\end{array}$ & $\begin{array}{c}\text { Malolactic } \\
\text { Ambient }\end{array}$ & $\begin{array}{c}\text { Stabilization } \\
\text { Ambient }\end{array}$ \\
\hline Calistoga & 65.3 & 54.5 & 54.5 \\
Central Coast & 66.2 & 53.8 & 53.8 \\
Foothills & 65.3 & 54.5 & 54.5 \\
Healdsburg & 64.0 & 53.4 & 53.4 \\
Hopland & 64.0 & 51.4 & 51.4 \\
Lodi & 68.7 & 55.2 & 55.2 \\
Livermore & 66.7 & 53.8 & 53.8 \\
Napa & 61.9 & 50.0 & 50.0 \\
Paso Robles & 66.6 & 54.1 & 54.1 \\
Santa Rosa & 64.0 & 53.4 & 53.4 \\
Sonoma & 64.0 & 53.4 & 53.4 \\
St. Helena & 61.9 & 50.0 & 50.0 \\
Ukiah & 66.2 & 50.4 & 50.4 \\
\hline
\end{tabular}

Similar calculations are performed to determine energy use in the next two stages of winemaking for the benchmark: malolactic fermentation heating requirements and cold stabilization cooling requirements.

The energy required for aging and storage is based on production variables, particularly how much wine is stored in a twelve month period. The benchmark winery assumes the most efficient winery uses underground caves for storage, which limits the energy use in this section of the winery to energy for fans and humidification only. 
Bottling energy requirements are based on the estimated time that the bottling equipment runs annually, estimated at 52 weeks per year, at 40 hours per week for seven weeks and 48 hours per week for five weeks ${ }^{3}$. This time is the default value used in the model. However, the values may be changed by the user in the optional input sheet to more closely model their individual winery.

Pumping energy is made up of several parts: the energy required for pumping wine, water, cooling water, hot water, and wastewater (if water is treated onsite). Pumping energy for wine for the benchmark winery is based on the production variables input by the user. Cooling and hot water pumping for the benchmark winery are calculated based on assumptions about equipment running time but linked back to production input variables. For example, we estimated for the reference winery, hot water systems for malolactic fermentation will run for 4 months per year at 16 hours per day. Hot water for barrel cleaning, on the other hand, is estimated to require eight hours of pumping per day year round for the reference winery, while pumping for bottling lines cleaning was estimated to run three hours per day. We modeled the reference winery wastewater treatment system to be an aeration pond system, where only water pumping was required, at a rate of $0.034 \mathrm{kWh} /$ case of wine produced. Each of these numbers was obtained partly through discussions with various winemakers such as those at Fetzer Vineyards (Fetzer, 2004).

Heating requirements for hot water production was based on the amount of hot water required by the winery (which is described below in the Water Modeling Section) and a $90 \%$ efficient boiler.

Based on information from several audits, as well as our literature search, we estimated that the reference winery would require about $12 \%$ electricity for lighting requirements, about $5 \%$ for office equipment and workshops, and about $1 \%$ for other miscellaneous uses not included elsewhere in the model, while space heating would require an additional $1.5 \%$ of fuel. Propane used for forklifts was linked directly to production input.

\section{Water Modeling}

For water, LBNL worked with Fetzer Vineyards to determine the water use for each section of the winery in Hopland, CA, including: the "winery" (which includes fermentation, malolactic fermentation, and cold stabilization), crush pad, storage areas, refrigeration, hot water, barrel rooms, bottling, and all non-production uses. Fetzer's winery in Hopland is a much-below average user of water compared to the industry average on a gallon per barrel-produced basis. To construct the benchmark winery for the most efficient winery in water use, we subtracted out the water savings associated with all efficiency measures that had not yet been implemented at the Hopland facility to obtain the benchmark performance.

\footnotetext{
3 These numbers were based on best available data at the time of our project.
} 


\section{Energy Efficiency Opportunities}

In addition to evaluating overall performance and providing benchmarking scores for energy use (the EII) and water use (the WII) that compare energy and water use to the reference winery, BEST Winery provides a menu of opportunities for energy and water efficiency. This menu can be used to examine specific energy efficiency opportunities and to identify a set of possible measures that can help wineries achieve maximum benefit.

The following list of efficiency measures included in BEST Winery is common to wineries and many industrial facilities:

- Water

- Refrigeration,

- Pumping,

- Compressed Air,

- Motors,

- Lighting,

- Hot Water Supply,

- Cogeneration (Combined Heat and Power), and

- Miscellaneous Electric and Fuels.

The individual measures are each described below in their respective section. For each measure, typical energy or water savings, capital costs and payback period are provided. The measures span a wide range of applicability, both in system type and in design and operation, i.e., for new construction to maintenance. The estimates for energy or water savings and costs are necessarily based on past experiences in the wine and other industries. These are used in BEST Winery; however, actual performance and very specific characteristics for the user's winery may go beyond the capabilities of BEST Winery; these are not included in the results. Hence, BEST Winery gives an estimate of actual results for a preliminary evaluation of cost effective projects for the user's winery; for a more detailed and exact assessment, a specialized engineer or contractor should be consulted.

\subsection{Refrigeration}

Refrigeration for process cooling, i.e., fermentation, cold stabilization, and cold storage, accounts for much of the electricity used in wine making. The refrigeration energy efficiency measures listed here span a wide range of applicability, both in terms of refrigeration system types and the system design and operation scenarios when the measure might be considered, i.e. new construction to maintenance. The applicability of these refrigeration energy efficiency measures may depend on the refrigeration system size: "small/medium" refers to systems less than 100 tons, generally R-22 for "commercial/light industrial" applications, and "large" refers to systems 100 tons and up, generally ammonia (R-717) for "industrial” applications. 
As in other measures, the estimates for energy savings and costs of the refrigeration energy efficiency measures listed below are necessarily based on past experiences in the wine and other industries. These were used as input in BEST Winery. However, actual performance and very specific characteristics of the winery may also influence the results.

In general, it is important to note that for winery refrigeration systems:

- Proper maintenance, advanced control systems and operator training are areas that can pay big dividends.

- Small and medium sized winery refrigeration compressors and condensers must be sized for the crush, which lasts only six to eight weeks of the year. Therefore, systems are generally greatly oversized for the balance of the year and efficient operation at reduced capacity is an important area for improvement.

- Because major energy use is of short duration, great care should be exercised in system design. Without great care, energy efficiency measures that pay back quickly in other industries may have very extended payback periods for wineries. For example, oversized condensers, variable speed drives (VSDs) on condensers or VSDs on compressors, which are expensive investments, must be evaluated under the annual operating conditions predicted at the winery (Leue, 2004).

We have grouped refrigeration measures into four sections: system changes; compressors; condensers; and evaporators. System-type measures refer to measures that affect the overall refrigeration system performance and/or system load, e.g., controls, pipe and tank insulation, tight sealing doors and efficient lighting systems. Compressor, evaporator, and condenser-type measures are considered specific to these equipment components, yet understood to effect the system overall.

\section{System Changes}

Trigeneration. In BEST Winery, we show trigeneration in the refrigeration section because it lowers refrigeration energy use. However, the measure is included in a separate Worksheet labeled EE-CHP in BEST Winery, and in Section 7.9, below. Savings and investments are only included once (in the EE-CHP Sheet). Please see these sections for more information on trigeneration.

Reduce wattage lighting/occupancy control. Several energy efficiency measures relating to lighting are included in Section 5, below, as well as on the Worksheet entitled EE-Lighting in BEST Winery. However, in addition to the energy saved by reducing the electricity used in lighting, the reduction of lighting also reduces cooling load and refrigeration energy. In BEST Winery, reduction of lighting is linked to lighting measures on the EE-Lighting sheet, where degree of application is selected. Because costs are already accounted for on the EE-Lighting sheet, marginal costs for this measure are zero. Costs for each of the lighting measures are included in Section 5, below, on lighting. 
Monitor performance. Automated monitoring of energy performance is not yet common but is very beneficial in quantifying the opportunity to address poor part-load efficiency of many systems, and in showing deterioration, such as effect of low refrigerant charge. The cost of automated monitoring is fixed relative to the size of the system and may be minor on a new system, where much of the data can be obtained from the control system. The monitoring system should have the ability to provide system and component level information to operating staff as well as high-level performance summaries for management (Scott, 2004). We estimate savings of $3 \%$ for the energy used in refrigeration by applying this measure.

Monitor refrigerant charge. Low refrigerant charge affects many small direct expansion (DX) systems, and can also exist without obvious indicators on larger flooded or recircirculation systems. Without this measure, the system will keep running until it can't keep up any longer. This measure generally isn't applicable to large ammonia systems, but can be substantial if applicable and unnoticed. Scott (2004) estimates one in six DX systems has a low charge (or sometimes overcharge) situation sufficient to increase refrigeration energy usage by $20 \%$. We conservatively estimate refrigeration savings of $10 \%$ wherever this measure is applied.

Monitor suction line filters. There are multiple reasons to monitor suction line filters. Debris will cause a pressure drop, but it is also important to know if anything is being carried out along with the returning vapor. If there is, there is most likely erosion occurring on the internal surface of the pipe which can lead to premature failure of the pipe. If debris is found, a corrosion rate testing program should be implemented (Dettmers, 2004).

Generally this measure applies to smaller direct expansion (DX) systems, usually halocarbon not ammonia, although all systems can be monitored for unusual pressure drops that can originate from many sources (Scott, 2004). We estimate refrigeration systems savings from this measure to be about $3 \%$.

Monitor contaminants in refrigerant. Periodically monitor for contaminants (e.g., oil, water, etc.) to detect operating and maintenance problems with the system. We estimate refrigeration systems savings due to implementation of this measure to be $2 \%$.

Tank insulation. There are 3 primary types of tank insulation: Spray-on for large applications, foil over bubble wrap, and a rigid foam with an outer shell. Approximate energy savings generally vary from $20-33 \%$, depending on the type of insulation system. We estimate, on average, refrigeration systems would save about $25 \%$ wherever this measure is implemented.

Nighttime air cooling. Bringing in outside air brings in air at lower temperatures and provides savings due to reduced cooling electricity use (due to lower air temperatures and less mechanical cooling) and larger electricity cost savings due to lower peak use. We estimate energy savings for this measure to be about $20 \%$, applicable to warehouses (for aging and storing), offices and cold stabilization only, where outside air circulation 
is not already required. Fermentation already requires that fresh air is recirculated because of the $\mathrm{CO}_{2}$ generated within the fermentation process.

Reduced infiltration load from door closings. Though proper door management and tight sealing doors, energy requirements for refrigeration will be reduced due to reductions in infiltration. Based on BEST Winery, undesired infiltration losses account for approximately $21 \%$ of refrigeration energy in fermentation and cold stabilization ${ }^{4}$. We assume $15 \%$ of the total refrigeration energy could be saved due to proper door management.

Building Shell - reflective roofing materials. The building shell can serve as insulation from the weather (either hot or cold). The use of a reflective coating on the roof of buildings in sunny, hot climates like those found in California, can save on air conditioning costs inside. Two medical offices in Northern California used reflective roofs on their buildings and found summertime daily air-conditioning savings of 13 and $18 \%$ and reduced demand of 8 and 12\% (Konopacki et al., 1998). Primary factors that influence energy savings include location, weather, roof insulation, air conditioning efficiency and building age. We estimate savings to be $15 \%$ on cooling requirements in aging and storing, as well as office buildings. Cooling requirements in aging and storing and office buildings is approximately $23 \%$ of total refrigeration energy. Parker and Barkaszi (1994) estimate the overall costs to be about $\$ 1$ per square foot.

Building \& pipe Insulation and Vapor Barrier Integrity. The integrity of insulation and vapor barriers may be inspected through the use of thermography. Replace degraded insulation and add insulation whenever possible. A thermographic camera can be used to see areas where the insulation has degraded, often because of moisture intrusion into the insulation. If the vapor barrier is broken, you will see water running down the walls or ice balls hanging from the point of rupture. Cost effectiveness of increasing insulation requires simulation, e.g., with 3Eplus software (Dettmers, 2004). We estimate refrigeration systems savings from this measure to be about $10 \%$.

Size fan and motors more efficiently. As described in Section 7.4, below, motors and pumps that are sized inappropriately result in unnecessary energy losses. The same applies for fans and motors for the refrigeration system. Where peak loads can be reduced, motor and fan size can also be reduced. Correcting for motor over-sizing saves $1.2 \%$ of on the motor electricity consumption where applied (on average for the U.S. industry), and even larger percentages for smaller motors (Xenergy, 1998). It can be higher for individual motor systems. We assume similar savings for refrigeration resizing.

Electrodialysis. Electrodialysis uses selectively permeable membranes and an electric current to remove tartrates from wine that would generally otherwise undergo cold stabilization to remove these tartrates. Electrodialysis uses only about $12 \%$ of the

\footnotetext{
${ }^{4}$ Fresh air is required during indoor fermentation for worker safety due to the exhausted $\mathrm{CO}_{2}$ from the process. These air requirements are regulated and cannot be reduced. We estimate any additional infiltration to be undesired, and include only that air reduction in our model.
} 
energy used in cold stabilization, because no freezing and reheating is required (Dahlberg, 2004; Fetzer, 2004). In addition, reheating of wine after cold stabilization is no longer needed, saving yet more energy.

Currently, replacement of the membranes required in electrodialysis is quite expensive, making operation costs about equal to the cost savings achieved by electricity reduction, when electricity is valued at about $\$ 0.10$ per kWh (Dahlberg, 2004; Fetzer, 2004). However, WineSecrets, the major manufacturer of electrodialysis units in the U.S., claims savings achieved from wine that would be lost in cold stabilization make the process economical. They claim savings of $0.5 \%$ of wine, otherwise lost during cold stabilization. Currently, we have estimated costs to be $\$ 4.16 / \mathrm{kWh}$ saved, excluding savings from reduced wine loss. In BEST Winery, this number can be changed by the user, however, to account for savings due to reductions in wine loss to get a better estimate of payback period. The cost of $\$ 4.16$ per $\mathrm{kWh}$ saved is for a large unit processing 3000 gallons per hour. A smaller winery may have lower first costs as well as a lower maintenance contract and a better payback period, as well.

WineSecrets electrodialysis systems range from 400 gallons per hour for approximately $\$ 150,000$, up to 3,000 gallons per hour for $\$ 800,000$ (Dahlberg, 2004). In addition, A maintenance contract that includes membrane replacement, as well as other costs such as water, discharge, nitric acid, and operational labor costs between \$ 0.025 and \$0.055 per gallon, depending on the size of the unit.

Cave for barrel storage. Caves can be an alternative to above-ground buildings for wine storage. They provide an ideal environment for aging and storing wine, with almost constant temperatures year-round (typically about 60 degrees F) and a humidity of $80-90 \%$. Some wineries have estimated a 7-year payback for digging a cave (Franson, 2000). Obviously, the payback period for this measure is shorter for building new caves rather than for replacing an already existing building with a new cave. Magorian Mine Services estimate digging a cave typically costs around \$100 per square foot, while concrete masonry block buildings typically cost $\$ 91$ per square foot and super-insulated butler buildings cost $\$ 66$ per square foot (Black, 2002). For our calculations, we use an average of these two types of buildings to estimate typical additional costs of building a cave. We estimate savings based on electricity used to cool a warehouse building, which are no longer required for caves.

\section{Compressors}

Control system/scheduling of compressors. Existing compressors generally have some controls but their computerized controls often only mimic electro-mechanical set points. Savings from this measure come from specific enhanced strategies and set points, such as optimizing compressor operation (if there are multiple parallel screw compressors) to reduce part-load inefficiency or floating suction set point (Scott, 2004). Baseloading with screw compressors and trimming with reciprocating compressors are generally recommended. Screw compressors should not be operated below $50 \%$ of design capacity while reciprocating compressors can go much lower (Dettmers, 2004). 
This measure could involve better control of parallel machines with standard feedback control or some sort of load forecasting scheme not done yet for refrigeration (Scott, 2004). We estimate refrigeration systems savings from this measure to be about $3 \%$.

Floating Head Pressure (FHP) control versus fixed. Floating Head Pressure (FHP) involves additional fan power to reduce compressor power. This is a tradeoff, which means the control method and relative power is important. Overall, this is biggest the opportunity for reducing the energy consumption of refrigeration compressors, at least on smaller systems.

It is important not to allow head pressure to go too low. In ammonia refrigeration systems, certain processes in the system need a minimum head pressure. For example, liquid injection oil cooling often needs a minimum head pressure of around 135 psig. Other constraints may be needed for hot gas at a certain pressure/temperature to be able to meet defrost loads. Sometimes, lowering head pressure is simply an operational change, but often an additional compressor needs to be added to achieve it. In addition, there is a balance point in most systems when the extra energy added in fan power on the condenser exceeds the energy saved at the compressor (Dettmers, 2004). We estimate refrigeration systems savings from this measure to be about $4 \%$.

Adjustable Speed Drives (ASDs)/Variable Frequency Drives (VFDs) on compressor motors. ASDs/VFDs used below a part-load ratio of approximately 0.95 on a screw compressor deliver equal capacity with lower electrical power requirements than a fixed speed compressor. At a part-load ratio of $27 \%$, the variable speed drive operation requires $40 \%$ less electrical power than the fixed speed case - each providing equal refrigeration capacity. Note that at full-load, the variable frequency drive is approximately 3\% less efficient than the fixed speed drive case due to drive losses (Jekel, 2004b). We estimate refrigeration systems savings from this measure to be about $10 \%$.

\section{Condensers}

Adjustable Speed Drives (ASDs)/Variable Frequency Drives (VFDs) on condenser fans. From the standpoint of establishing a condenser operating strategy, the single greatest impact on energy efficiency is the choice of condenser fan capacity modulation. Prior to applying condenser fan ASDs/VFDs, it is important to evaluate the extent that the condensing (or head) pressure can be floated. Evaporative condenser operating strategies are dictated, in part, by the design of the connected refrigeration system and the selection of the condenser fan motor. The three most common strategies for condenser fan capacity control are: 1) on/off control with single-speed fans, 2) high/low/off control with 2-speed fans, 3) variable speed fans (Jekel, 2004a). We estimate refrigeration systems savings from this measure to be about $5 \%$. 


\section{Evaporators}

Install automatic purgers on evaporative condensers. Automatic purgers are used to remove air and other non-condensables. On glycol/water chillers, it is recommended to purge air and other non-condensables from the system at least quarterly, possibly more during periods of heavy use (Dettmers, 2004). As a rule, 1\% non-condensables could result in $1 \%$ efficiency loss, depending on the refrigerant used and the lift (Papar, 2004). We estimate refrigeration systems savings from this measure to be about $5 \%$.

Adjustable Speed Drives (ASDs)/Variable Frequency Drives (VFDs) on evaporator (air unit) fans. ASDs/VFDs, continuous fixed speed (FS), and duty cycling (DC) represent three primary types of evaporator fan speed control strategies. Of the three, ASD/VFD has the best efficiency advantage at low part-load operating conditions, yet to be cost-effective there must be enough hours of part-load operation to "pay" for the drive (Jekel, 2004c). We estimate refrigeration systems savings from this measure to be about $4 \%$.

Cycle evaporative (air unit) fans. Evaporator (air unit) fans should be cycled as permissible by the system (evaporator), but operated occasionally to prevent stratification of the air in the space. On certain types of evaporators (flooded \& recirculated), fans should not be shut off until an extended period of solenoid off time is reached. Otherwise, it is possible to leave an evaporator sitting full of liquid ammonia. Stratification of the air means that the product(s) at the top of a warehouse could warm up beyond the specified temperature level and product(s) could be lost (Dettmers, 2004). Instead of shutting down the fan for various concerns (e.g., mold, start-up costs or lack of warning of need), a set-back mode may be used or a small dehumidifier coil/system may be installed for non-occupied modes. This measure requires integration with other system controls (Scott, 2004). We estimate refrigeration systems savings from this measure to be about $2 \%$.

\subsection{Pumping}

Pumping systems account for nearly $20 \%$ of the world's electrical energy demand (Hydraulic Institute and Europump, 2001; Xenergy, 1998). In the U.S., pumping systems account for about $25 \%$ of the electricity used in manufacturing. In wineries, pumping energy needs may account for between 10 and $25 \%$ of electricity consumption. Pump efficiencies may vary between $15 \%$ and $90 \%$, demonstrating potential for efficiency improvement. Studies have shown that over $20 \%$ of the energy consumed by these systems could be saved through equipment or control system changes (Xenergy, 1998).

In a winery, pumps are not only used to pump product, but pumps are also found in refrigeration systems and water systems. Hence, there are different pumps used within a winery, e.g. centrifugal, progressive cavity, lobe, flexible impeller, diaphragm, peristaltic and reciprocating piston pumps (Phillips, 2002). For product handling, the choice of pump is particularly important. For example, lobe pumps are suitable for 
pumping fluids with suspended solids (e.g. must and lees), while centrifugal pumps are mostly used for moving wine between tanks or for pumping water.

It is important to note that initial costs are only a fraction of the life cycle costs of a pump system. Energy costs, and sometimes operations and maintenance costs, are typically much more important in the lifetime costs of a pump system. In general, for a pump system with a lifetime of 20 years, the initial capital costs of the pump and motor make up merely $2.5 \%$ of the total costs (Best Practice Programme, 1998). Energy costs, however, make up about $95 \%$ of the lifetime costs of the pump. Maintenance costs compose the remaining $2.5 \%$. Hence, the initial choice of a pump system should be highly dependent on energy cost considerations rather than on initial costs.

Pumping systems consist of a pump, a driver, pipe installation and controls (such as adjustable speed drives or throttles) and are a part of the overall motor system. Using a "systems approach" on the entire motor system (pumps, compressors, motors and fans) was also discussed in section 5.1.1. For example, higher efficiency motors also increase the efficiency of the associated pump by 2 to $5 \%$. In this section, the pumping systems are addressed; for optimal savings and performance, it is recommended that the systems approach incorporating pumps, compressors, motors and fans be used.

There are two main ways to increase pump efficiency, aside from reducing use. These are: 1) reducing the friction in dynamic pump systems (not applicable to static or "lifting" systems) and 2) adjusting the system so that it draws closer to the best efficiency point (BEP) on the pump curve (Hovstadius, 2002). Correct sizing of pipes, surface coatings or polishings and adjustable speed drives, for example, may reduce the friction loss, increasing energy efficiency. Correctly sizing the pump and choosing the most efficient pump for the applicable system will push the system closer to the best efficiency point on the pump curve.

Maintenance and Monitoring. Inadequate maintenance at times lowers pump system efficiency, causes pumps to wear out more quickly and increases costs. Better maintenance will reduce these problems and save energy. Monitoring in conjunction with maintenance can be used to detect problems and determine solutions to create a more efficient system. Monitoring can determine clearances that need be adjusted, indicate blockage, impeller damage, inadequate suction, operation outside preferences, clogged or gas-filled pumps or pipes, or worn out pumps. Monitoring should include wear monitoring, vibration analyses for main pumps, pressure and flow monitoring, current or power monitoring, and distribution system inspection for scaling or contaminant build-up. Proper maintenance includes the following (Hydraulic Institute, 1994; LBNL et al., 1999):

- Replacement of worn impellers, especially in caustic or semi-solid applications.

- Bearing inspection and repair.

- Bearing lubrication replacement, once annually or semiannually.

- Inspection and replacement of packing seals. Allowable leakage from packing seals is usually between two and sixty drops per minute. 
- Inspection and replacement of mechanical seals. Allowable leakage is typically one to four drops per minute.

- Wear ring and impeller replacement. Pump efficiency degrades from 1 to 6 points for impellers less than the maximum diameter and with increased wear ring clearances (Hydraulic Institute, 1994).

- Pump/motor alignment check.

Typical energy savings for monitoring and maintenance are estimated to be between 2 and $7 \%$ of pumping electricity. However, inefficient pumping systems may show higher savings. Paybacks are usually immediate to one year (Xenergy, 1998; U.S. DOE/OIT, 2002a). We assume investments of $\$ 0.10 / \mathrm{kWh}$-saved and savings of $5 \%$ of pumping energy use.

Reduce Pumping Need. Holding tanks can be used to equalize the flow over the production cycle, enhancing energy efficiency and potentially reducing the need to add pump capacity. In addition, bypass loops and other unnecessary flows should be eliminated. Each of these steps saves 5 to $10 \%$ of pump system electricity consumption, on average for the U.S. industry (Easton Consultants, 1995).

In smaller, new wineries, a design based on gravity can reduce the need for pumping by locating the tanks in such a way that no pumping is needed. The presses are located over the fermentation tanks, which are located over the storage facilities (cellar). It is also claimed that such a layout is easier on the grapes. Selected wineries are designed on the use of gravity, e.g. Byron (Santa Maria), Greystone (Napa), Niebaum-Coppola (Napa), Lemelson Winery (Oregon), and Willakenzie Estate (Oregon) (Hall, 1999). Due to costs, this practice is not recommended for existing wineries, but would be applicable to newly designed wineries if the local conditions allow such a design. Also, it may not be applicable to all kinds of wine (Hall, 1999). Several wineries specializing in Pinot Noir are using this technology where the grape needs a gentler knead. Hence, a gravity design may be most applicable to small, specialized wineries. The energy savings are estimated at $5-10 \%$ of total energy use in wineries. This investment is driven by wine quality and not by energy savings, and the additional investments (compared to a standard design) are strongly dependent on the site of the winery.

Controls. The objective of any control strategy is to shut off unneeded pumps or reduce load until needed. Remote controls enable pumping systems to be started and stopped more quickly and accurately when needed, and reduce the required labor.

In 2000, Cisco Systems (CA) upgraded the controls on its fountain pumps that turn off the pumps during peak hours (CEC and U.S. DOE/OIT, 2002). The wireless control system was able to control all pumps simultaneously from one location. The project saved $\$ 32,000$ and $400,000 \mathrm{kWh}$ annually, representing a savings of $61.5 \%$ of the fountain pumps' total energy consumption. With a total cost of $\$ 29,000$, the simple payback was 11 months. In addition to energy savings, the project reduced maintenance costs and increased the pumping system's equipment life. 
Typical energy-efficiency improvement potential is estimated at $30 \%$ for control systems, with a specific investment of $\$ 0.11 / \mathrm{kWh}$-saved.

Correct Sizing of Pump. Pumps that are sized inappropriately result in unnecessary losses. Where peak loads can be reduced, pump size can also be reduced. Correcting for pump oversizing saves 15 to $25 \%$ of electricity consumption for pumping (on average for the U.S. industry) (Easton Consultants, 1995). In addition, pump load may be reduced with alternative pump configurations and improved O\&M practices.

Where pumps are dramatically oversized, speed can be reduced with gear or belt drives or a slower speed motor. Paybacks for implementing these solutions are typically less than one year (U.S. DOE/OIT, 2002). We estimate the typical savings at $20 \%$ with an investment of $\$ 0.12 / \mathrm{kWh}$.

Correct Sizing of Pipes. Similar to pumps, undersized pipes also result in unnecessary losses. The pipework diameter is selected based on the economy of the whole installation, the required lowest flow velocity, the minimum internal diameter for the application, the maximum flow velocity to minimize erosion in piping and fittings and plant standard pipe diameters. Increasing the pipe diameter may save energy but must be balanced with costs for pump system components. Easton Consultants (1995) and others in the pulp and paper industry (Xenergy, 1998) estimate retrofitting pipe diameters saves 5 to $20 \%$ of their energy consumption, on average for the U.S. industry. Energy savings and investments will depend strongly on the layout of the winery and site.

Correct sizing of pipes should be done at the design or system retrofit stages where costs may not be restrictive. This measure is often not cost-effective in existing systems. Therefore, the measure is not included in this assessment, but should be considered in the design of a new facility.

More Efficient Pumps. According to inventory data, about $16 \%$ of pumps used in the U.S. are more than 20 years old. A pump's efficiency may degrade 10 to $25 \%$ in its lifetime (Easton Consultants, 1995). Newer pumps are 2 to 5\% more efficient than older models. However, industry experts claim the problem is not necessarily the age of the pump but that the process has changed and the pump does not match the operation. Replacing a pump with a new efficient one saves between 2 to $10 \%$ of its energy consumption (Elliot, 1995). Higher efficiency motors have also been shown to increase the efficiency of the pump system 2 to $5 \%$ (Tutterow, 1999).

A number of pumps are available for specific pressure head and flow rate capacity requirements. Choosing the right pump often saves both in operating costs and in capital costs (of purchasing another pump). For a given duty, selecting a pump that runs at the highest speed suitable for the application will generally result in a more efficient selection as well as the lowest initial cost (Hydraulic Institute and Europump, 2001). Exceptions to this include slurry-handling pumps, high speed specified pumps or where the pump would need a very low minimum net positive suction head at the pump inlet. 
Precision castings, coatings, polishings. The use of castings, coatings or polishing reduces surface roughness that, in turn, increases energy efficiency. It may also help maintain efficiency over time. This measure is more effective on smaller pumps. One case study in the steel industry analyzed the investment in surface coating on the mill supply pumps (350 kW pumps). They determined that the additional cost of coating, $\$ 1200$ (U.S.) would be paid back in 5 months by energy savings of $\$ 2700$ (U.S.) (or 36 MWh, 2\%) per year (Hydraulic Institute and Europump, 2001). Energy savings for coating pump surfaces are estimated to be 2 to $3 \%$ over uncoated pumps (Best Practice Programme, 1998).

Use Multiple Pumps. Often using multiple pumps is the most cost-effective and most energy-efficient solution for varying loads, particularly in a static head-dominated system. Installing parallel systems for highly variable loads saves 10 to $50 \%$ of the electricity consumption for pumping (on average for the U.S. industry) (Easton Consultants, 1995). Variable speed controls should also be considered for dynamic systems. Parallel pumps also offer redundancy and increased reliability.

Trimming impeller (or shaving sheaves). If a large differential pressure exists at the operating rate of flow (indicating excessive flow), the impeller (diameter) can be trimmed so that the pump does not develop as much head. In the food processing, paper and petrochemical industries, trimming impellers or lowering gear ratios is estimated to save as much as $75 \%$ of the electricity consumption for that pump (Xenergy, 1998).

In one case study in the chemical processing industry, the impeller was reduced from $320 \mathrm{~mm}$ to $280 \mathrm{~mm}$, which reduced the power demand by more than 25\% (Hydraulic Institute and Europump, 2001). Annual energy demand was reduced by 83 MWh (26\%). With an investment cost of \$390 (U.S.), the payback on energy savings alone was 23 days. In addition to energy savings, maintenance costs were reduced, system stability was improved, cavitation reduced and excessive vibration and noise were eliminated.

In another similar case study, Salt Union Ltd., the largest salt producer in the UK, trimmed the diameter of the pump impeller at its plant from $320 \mathrm{~mm}$ to $280 \mathrm{~mm}$ (13 to 11 inches) (Best Practice Programme, 1996b). After trimming the impeller, they found significant power reductions of $30 \%$, or $197,000 \mathrm{kWh}$ per year (710 GJ/year), totaling 8,900 GBP (\$14,000 1994 U.S.). With an investment cost of 260 GBP (\$400 1993 U.S.), and maintenance savings of an additional 3,000 GBP (\$4,600 1994 U.S.), this resulted in a payback of 8 days (11 days from energy savings alone). In addition to energy and maintenance savings, like the chemical processing plant, cavitation was reduced and excessive vibration and noise were eliminated. With the large decrease in power consumption, the $110 \mathrm{~kW}$ motor could be replaced with a $75 \mathrm{~kW}$ motor, with additional energy savings of 58GJ (about 16,000 kWh) per year.

Adjustable Speed Drives (ASDs). It is important to match the speed of the pump to the load requirement, because energy use is approximately proportional to the cube of 
the flow rate ${ }^{5}$. Small reductions in flow that are proportional to pump speed may yield large energy savings. However, throttling valves should always be avoided. Extensive use of throttling valves or bypass loops may be an indication of an oversized pump (Tutterow et al., 2000). ASDs or variable speed drives or on/off regulated systems always save energy compared to throttling valves (Hovstadius, 2002). In addition, the installation of ASDs improves overall productivity, control and product quality, and reduces wear on equipment, thereby reducing future maintenance costs.

According to inventory data collected by Xenergy (1998), 82\% of pumps in U.S. industry have no load modulation feature (or ASD). Similar to being able to adjust load in motor systems, including modulation features with pumps is estimated to save between 20 and 50\% of pump energy consumption, at relatively short payback periods, depending on pump size, load and load variation (Xenergy, 1998; Best Practice Programme, 1996a). As a general rule of thumb, unless the pump curves are exceptionally flat, a 10\% regulation in flow should produce pump savings of $20 \%$ and $20 \%$ regulation should produce savings of 40\% (Best Practice Programme, 1996a).

Due to the wide variety of pump applications and hence variety in flows in a winery it is difficult to estimate typical savings. As a low estimate we assume efficiency improvements of $20 \%$ on all applicable pumps systems. The payback of installing an ASD depends strongly on the pump size and expected savings. Based on audits of wineries in California we assume an average investment of $\$ 0.3 / \mathrm{kWh}$-saved.

Replace Belt Drives. Inventory data suggest 4\% of pumps have V-belt drives, many of which can be replaced with direct couplings to save energy (Xenergy, 1998). Based on assessments in several industries, including wineries, savings are estimated at $1 \%$ of all electricity used in motor systems. Investment costs are estimated at $\$ 0.10 / \mathrm{kWh}$-saved with a simple payback period of 0.7-0.8 years.

\subsection{Compressed Air}

Compressed air is used mainly in the bottling facility, but may also be used elsewhere in the winery (e.g. pressing). In the model winery energy use for compressed air systems is estimated at $7 \%$ of total electricity use for a winery that has a bottling plant. Energy savings from system improvements can range from $20 \%$ to $50 \%$ or more of electricity consumption (EP, 2004a) for compressed air systems.

Compressed air is probably the most expensive form of energy used in an industrial plant because of its poor efficiency. Typically, efficiency for compressed air systems from start to end-use is around 10\% (LBNL et al., 1998). Because of this inefficiency, if compressed air is used, it should be of minimum quantity for the shortest possible

\footnotetext{
5 This equation applies to dynamic systems only. Systems that solely consist of lifting (static head systems) will accrue no benefits from (but will often actually become more inefficient) ASDs because they are independent of flow rate. Similarly, systems with more static head will accrue fewer benefits than systems that are largely dynamic (friction) systems. More careful calculations must be performed to determine actual benefits, if any, for these systems.
} 
time, constantly monitored and weighed against alternatives. In addition to the measures detailed below, many other motor-directed measures can also be applied to the compressors. Many opportunities to reduce energy in the compressed air systems are not prohibitively expensive; payback periods for some options are extremely short.

Maintenance of Compressed Air Systems. Inadequate maintenance can lower compression efficiency and increase air leakage or pressure variability, as well as lead to increased operating temperatures, poor moisture control, and excessive contamination. Improved maintenance will reduce these problems and save energy. Proper maintenance includes the following (LBNL et al., 1998):

- Regulators sometimes contribute to the biggest savings in compressed air systems. By properly sizing regulators, compressed air will be saved that is otherwise wasted as excess air. Also, it is advisable to specify pressure regulators that close when failing.

- Keep the compressor and intercooling surfaces clean and foul-free. Blocked filters increase the pressure drop. By inspecting and periodically cleaning filters, the pressure drop may be kept low. Seek filters with just a 1 psig pressure drop over 10 years. The payback for filter cleaning is usually under 2 years (Ingersoll-Rand, 2001). Fixing improperly operating filters will also prevent contaminants from entering into tools and causing them to wear out prematurely. Generally, when pressure drop exceeds 2 to 3 psig, replace the particulate and lubricant removal elements, and inspect all systems at least annually. Also, consider adding filters in parallel that decrease air velocity, and, therefore, decrease air pressure drop. A $2 \%$ reduction of annual energy consumption in compressed air systems is projected for more frequent filter changing (Radgen and Blaustein, 2001). However, one must be careful when using coalescing filters; efficiency drops below 30\% of design flow (Scales, 2002).

- Keep motors properly lubricated and cleaned. Poor motor cooling can increase motor temperature and winding resistance, shortening motor life, in addition to increasing energy consumption. Compressor lubricant should be changed every 2 to 18 months and checked to make sure it is at the proper level. In addition to energy savings, this can help avoid corrosion and degradation of the system.

- Inspect fans and water pumps for peak performance.

- Inspect drain traps periodically to ensure they are not stuck in either the open or closed position and are clean. Some users leave automatic condensate traps partially open at all times to allow for constant draining. This practice wastes substantial energy and should never be undertaken. Instead, install simple pressure driven valves. Malfunctioning traps should be cleaned and repaired instead of left open. Some auto drains, such as float switch or electronic drains, do not waste air. Inspecting and maintaining drains typically has a payback of less than 2 years (Ingersoll-Rand, 2001).

- Maintain the coolers on the compressor to ensure that the dryer gets the lowest possible inlet temperature (Ingersoll-Rand, 2001).

- If using compressors with belts check belts for wear and adjust them. A good rule of thumb is to adjust them every 400 hours of operation. 
- Replace air lubricant separators according to specifications or sooner. Rotary screw compressors generally start with their air lubricant separators having a 2 to 3 psid pressure drop at full load. When this increases to 10 psid, change the separator (LBNL at al., 1998).

- Check water-cooling systems for water quality ( $\mathrm{pH}$ and total dissolved solids), flow, and temperature. Clean and replace filters and heat exchangers per manufacturer's specifications.

- Minimize leaks (see also Leaks section, below).

- Specify pressure regulators that close when failing.

- Check applications requiring compressed air for excessive pressure, duration or volume. Regulate these applications, either by production line sectioning or by pressure regulators on the equipment itself. Use a quality pressure regulator for tools that are not required to operate at maximum system pressure. Poor quality regulators tend to drift and lose more air. The unregulated tools operate at maximum system pressure at all times and waste excess energy. System pressures operating too high also result in shorter tool life and higher maintenance costs. Case studies demonstrated that the payback period for this measure would be shorter than half year (IAC, 2002).

Monitoring $^{6}$. Proper monitoring (and maintenance) can save a lot of energy and money in compressed air systems. Proper monitoring includes the following:

- Pressure gauges on each receiver or main branch line and differential gauges across dryers, filters, etc.

- Temperature gauges across the compressor and its cooling system to detect fouling and blockages.

- Flow meters to measure the quantity of air used.

- Dew point temperature gauges to monitor the effectiveness of air dryers.

- $\mathrm{kWh}$ meters and hours run meters on the compressor drive.

- Compressed air distribution systems should be checked when equipment has been reconfigured to be sure no air is flowing to unused equipment or obsolete parts of the compressed air distribution system.

- Check for flow restrictions of any type in a system, such as an obstruction or roughness. These require higher operating pressures than are needed. Pressure rise resulting from resistance to flow increases the drive energy on the compressor by $1 \%$ of connected power for every 2 psi of differential (LBNL et al., 1998; Ingersoll-Rand, 2001). Highest pressure drops are usually found at the points of use, including undersized or leaking hoses, tubes, disconnects, filters, regulators, valves, nozzles and lubricators (demand side), as well as air/lubricant separators, after-coolers, moisture separators, dryers and filters.

- Check for compressed air use outside production hours.

- Turn off unnecessary compressed air. Equipment that is no longer using compressed air should have the air turned off completely. This can be done using a simple solenoid valve (Scales, 2002). Check compressed air distribution

\footnotetext{
${ }^{6}$ Monitoring is not included as a separate measure in BEST for Wineries. Rather, maintenance and monitoring are grouped together as a single measure.
} 
systems when equipment has been reconfigured to be sure no air is flowing to unused equipment or obsolete parts of the compressed air distribution system.

Repair Leaks. Air leaks can be a significant source of wasted energy. A typical plant that has not been well maintained will likely have a leak rate equal to 20 to $50 \%$ of total compressed air production capacity (Ingersoll Rand, 2001; Price and Ross, 1989). Leak maintenance can reduce this number to less than 10\%. Overall, a 20\% reduction of annual energy consumption in compressed air systems is projected for fixing leaks (Radgen and Blaustein, 2001).

The magnitude of a leak varies with the size of the hole in the pipes or equipment. A compressor operating 2,500 hours per year at 6 bar (87 psi) with a leak diameter of 0.02 inches $(1 / 2 \mathrm{~mm})$ is estimated to lose $250 \mathrm{kWh} /$ year; $0.04 \mathrm{in}$. ( $1 \mathrm{~mm})$ to lose 1100 $\mathrm{kWh} /$ year; $0.08 \mathrm{in}$. (2 mm) to lose 4,500 kWh/year; and $0.16 \mathrm{in}$. (4 mm) to lose 11,250 kWh/year (CADDET, 1997a). An Industrial Assessment Center (IAC) study shows the payback period for this measure is generally shorter than two months (IAC, 2002).

In addition to increased energy consumption, leaks can make air tools less efficient, adversely affect production, shorten the life of equipment and lead to additional maintenance requirements and increased unscheduled downtime. Leaks cause an increase in compressor energy and maintenance costs.

The most common areas for leaks are couplings, hoses, tubes, fittings, pressure regulators, open condensate traps and shut-off valves, pipe joints, disconnects and thread sealants. The best way to detect leaks is to use an ultrasonic acoustic detector, which can recognize the high frequency hissing sounds associated with air leaks. After identification, leaks should be tracked, repaired and verified. Leak detection and correction programs should be ongoing efforts.

Reduce Pressure Drop. An excessive pressure drop will result in poor system performance and excessive energy consumption. Flow restrictions of any type in a system, such as an obstruction or roughness, require higher operating pressures than are needed. Pressure rise resulting from resistance to flow increases the drive energy on positive displacement compressors by 1\% of connected power for each 2 psi of differential (LBNL et al., 1998; Ingersoll-Rand, 2001). Highest pressure drops are usually found at the points of use, including undersized or leaking hoses, tubes, disconnects, filters, regulators, valves, nozzles and lubricators (demand side), and air/lubricant separators on lubricated rotary compressors and after-coolers, moisture separators, dryers and filters (supply side).

Minimizing pressure drop requires a systems approach in design and maintenance. Air treatment components should be selected with the lowest possible pressure drop at specified maximum operating conditions and best performance. Manufacturers' recommendations for maintenance should be followed, particularly in air filtering and drying equipment, which can have damaging moisture effects like pipe corrosion. Finally, the distance the air travels through the distribution system should be 
minimized. An IAC study shows that the payback period is shorter than three months for this measure (IAC, 2002).

Reduce compressed air usage. Turn off unnecessary compressed air. Equipment that is no longer using compressed air should have the air turned off completely. This can be done using a simple solenoid valve (Scales, 2002). Compressed air distribution systems should be checked when equipment has been reconfigured to be sure no air is flowing to unused equipment or obsolete parts of the compressed air distribution system.

Use sources other than compressed air; many operations can be accomplished more economically and efficiently using energy sources other than compressed air. Some industry engineers believe this measure has the largest potential for compressed air energy savings. Various options exist to replace compressed air use, including:

- Air motors should only be used for positive displacement.

- Cooling electrical cabinets: air conditioning fans should be used instead of using compressed air vortex tubes.

- Flowing high-pressure air past an orifice to create a vacuum: a vacuum pump system should be applied instead of compressed air venturi methods.

- Cooling, aspirating, agitating, mixing, or package inflating: use blowers instead of compressed air

- Cleaning parts or removing debris: brushes, blowers or vacuum pump systems or nozzles that are more efficient should be used instead of compressed air.

- Moving parts: blowers, electric actuators or hydraulics should be used instead of compressed air.

- Blowguns, air lances and agitation: low-pressure air should be used instead of high pressure compressed air.

- Efficient electric motors for tools or actuators: electric motors should be considered because they are more efficient than using compressed air (Howe and Scales, 1995). Some, however, have reported motors can have less precision, shorter lives, and lack safety. In these cases, using compressed air may be a better choice.

Numerous case studies in U.S. industries estimate an average payback period for replacing compressed air with other applications of 11 months (IAC, 2002).

Controls. Because of the large amount of energy consumed by compressors, whether in full operation or not, partial load operation should be avoided. For example, unloaded rotary screw compressors still consume 15 to 35\% of full-load power while delivering no useful work (LBNL et al. 1998). Centrifugal compressors are cost effective when operated at high loads (Castellow et al., 1997).

The objective of any control strategy is to shut off unneeded compressors or delay bringing on additional compressors until needed. All units that are on should be running at full-load, except for one. Positioning of the control loop is also important; reducing and controlling the system pressure downstream of the primary receiver can result in 
energy consumption of up to $10 \%$ or more (LBNL, et al., 1998). Energy savings for sophisticated controls are 12\% annually (Radgen and Blaustein, 2001). Start/stop, load/unload, throttling, multi-step, variable speed and network controls are options for compressor controls and described below.

Start/stop (on/off) is the simplest control available and can be applied to reciprocating or rotary screw compressors. For start/stop controls, the motor driving the compressor is turned on or off in response to the discharge pressure of the machine. They are used for applications with very low duty cycles. Applications with frequent cycling will cause the motor to overheat. Typical payback for start/stop controls is 1 to 2 years.

Load/unload control, or constant speed control, allows the motor to run continuously but unloads the compressor when the discharge pressure is adequate. In most cases, unloaded rotary screw compressors still consume 15 to $35 \%$ of full-load power while delivering no useful work (LBNL et al., 1998). Hence, load/unload controls can be inefficient.

Modulating or throttling controls allow the output of a compressor to be varied to meet flow requirements by closing down the inlet valve and restricting inlet air to the compressor. Throttling controls are applied to centrifugal and rotary screw compressors. Changing the compressor control from on/zero/off to a variable speed control can save up to 8\% per year (CADDET, 1997b). Changing the compressor control to a variable speed control can save up to 8\% per year (CADDET, 1997a).

Multi-step or part-load controls can operate in two or more partially loaded conditions. Output pressures can be closely controlled without requiring the compressor to start/stop or load/unload.

System controls work on multiple compressors. Single master sequencing system controls take individual compressor capacities on- and off-line in response to monitored system pressure demand and shut down any compressors running unnecessarily. System controls for multiple compressors typically offer a higher efficiency than individual compressor controls.

Reducing the Inlet Air Temperature. If the airflow is kept constant, reducing the inlet air temperature reduces energy used by the compressor. In many plants, it is possible to reduce inlet air temperature to the compressor by taking suction from outside the building. As a rule of thumb, each $5^{\circ} \mathrm{F}\left(3^{\circ} \mathrm{C}\right)$ will save $1 \%$ compressor energy (CADDET, 1997a; Parekh, 2000). A payback period of 2 to 5 years has been reported for importing fresh air (CADDET, 1997a). In addition to energy savings, compressor capacity is increased when cold air from outside is used. Case studies taken from the IAC database have found an average payback period for importing outside air of shorter than 1.7 years (IAC, 2002).

Adjustable Speed Drive. ASDs better match speed to load requirements for motor operations. There are various technologies to control the motor. The systems are offered by many suppliers and are available worldwide. Payback period may vary 
widely depending on the size of the motor system and use pattern. Implementing adjustable speed drives in rotary compressor systems can save $15 \%$ of the annual energy consumption (Radgen and Blaustein, 2001).

Sizing Pipe Diameter Correctly. Inadequate pipe sizing can cause pressure losses, increase leaks and increase generating costs. Pipes must be sized correctly for optimal performance or resized to fit the current compressor system. Increasing pipe diameter typically reduces annual energy consumption by 3\% (Radgen and Blaustein, 2001).

Heat Recovery for Water Preheating. As much as 80 to 93\% of the electrical energy used by an industrial air compressor is converted into heat. In many cases, a heat recovery unit can recover 50 to $90 \%$ of the available thermal energy for space heating, industrial process heating, water heating, makeup air heating, boiler makeup water preheating, industrial drying, industrial cleaning processes, heat pumps, laundries or preheating aspirated air for oil burners (Parekh, 2000). It's been estimated that approximately 50,000 Btu/hour of energy is available for each $100 \mathrm{cfm}$ of capacity (at full load) (LBNL et al., 1998). Paybacks are typically less than one year. Heat recovery for space heating is not as common with water-cooled compressors because an extra stage of heat exchange is required and the temperature of the available heat is lower. However, with large water-cooled compressors, recovery efficiencies of 50 to $60 \%$ are typical (LBNL et al., 1998). Implementing this measure saves up to $20 \%$ of the energy used in compressed air systems annually, when waste heat is recovered for hot water preparation (Radgen and Blaustein, 2001).

Replace Belt Drives. Inventory data suggests 4\% of pumps have V-belt drives, many of which can be replaced with direct couplings to save energy (Xenergy, 1998). Based on assessments in several industries, including wineries, savings are estimated at $4 \%$. Investment costs are estimated at $\$ 0.10 / \mathrm{kWh}$-saved with a simple payback period of 0.7-0.8 years.

Minimize Air Compressor Discharge Pressure. Discharge pressure at the air compressor outlet should be minimized for each compressor in the winery. Savings and payback periods will vary greatly if a compressor is able to be taken offline due to these changes; however we estimate savings to be $8 \%$, based on an audit performed at a California winery.

\subsection{Motors}

Motors and drives are used throughout a winery to operate heating, ventilation and cooling systems (HVAC), and to drive equipment, the refrigeration system, fans, and pumps. The following section applies to any system that uses motors, except for motors used in pumps, compressed air, and refrigeration are discussed in other sections.

Using a "systems approach" that looks at the entire motor system (e.g. pumps, compressors, motors, and fans) to optimize supply and demand of energy services often yields the most cost-effective savings. A systems approach analyzes both the supply 
and demand sides and how they interact, shifting the focus of the analysis from individual components to total system performance. This system approach is an important step to establish a company-wide motor efficiency policy. This approach includes several steps. First, locate and identify the motors and uses (e.g. pumps, fans) used in the manufacturing facility. Secondly, document the conditions and specifications of these motors. Thirdly, compare the needs and actual use of the system to determine the energy consumption rate by the motors, to determine the proper size. After the evaluation, to enable an easier decision making process, collect information on the upgrade or update of the system, including the cost of implementation and the anticipated annual savings. The final step is to monitor the performance of the upgraded/updated system and determine the actual costs savings (SCE, 2003). The measures identified below reflect aspects of this systems approach including matching speed and load (variable speed drives), sizing the system correctly, as well as upgrading system components.

Maintenance. The purposes of motor maintenance are to prolong motor life and to foresee a motor failure. The maintenance measures can be categorized as preventive and predictive ones. The preventive measures, to avoid the unexpected downtime of motors, include electrical consideration, voltage imbalance, motor ventilation, alignment, lubrication, and load consideration. The predictive maintenance programs are to observe temperature, vibration, and other data for the determination of a time to overhaul or replace a motor (Barnish et al, 1997). The saving by conducting regular maintenance could range from $2 \%$ to $30 \%$ of total system energy use (EP, 2004b).

Sizing of motors. Motors and pumps that are sized inappropriately result in unnecessary energy losses. Where peak loads can be reduced, motor size can also be reduced. Correcting for motor over-sizing saves $1.2 \%$ of motor electricity consumption applied (on average for the U.S. industry), and even larger percentages for smaller motors (Xenergy, 1998) and can be higher for individual motor systems.

High-Efficiency Motors and Drives. High efficiency motors reduce energy losses through improved design, better materials, tighter tolerances and improved manufacturing techniques. With proper installation, energy-efficient motors run cooler and consequently have higher service factors, longer bearing and insulation life and less vibration.

Typically, high efficiency motors are economically justified when exchanging a motor that needs replacement, but are not economically feasible when replacing a motor that is still working (CADDET, 1994; Price and Ross, 1989). Sometimes, though, according to case studies by the Copper Development Association (CDA, 2000), even working motor replacements can be beneficial. The payback period for individual motors varies based on size, load factor and running time. The best savings are achieved on motors running for long hours at high loads. When replacing retiring motors, payback periods are typically less than one year from energy savings alone (LBNL et al., 1998). The payback period is generally less than 3 years, depending on how long the motor is used. 
To be considered energy efficient in the U.S., a motor must meet performance criteria published by the National Electrical Manufacturers Association (NEMA). However, most manufacturers offer lines of motors that significantly exceed the NEMA-defined criteria, even those defined by NEMA as energy efficient (DOE, 2001). NEMA and other organizations are sponsoring a "Motor Decisions Matter" campaign to market NEMA-approved premium efficient motors to industry (NEMA, 2001). Even these premium efficiency motors can have a low payback period. It almost always makes sense not only to buy an energy efficient motor but also to buy the most efficient motor available (LBNL, 1998) when installing a new motor.

Replacing a motor with a high efficiency motor is often a better choice than rewinding a motor. The practice of rewinding motors currently has no quality or efficiency standards. The efficiency of a motor decreases after rewinding. A standard consideration is a $2 \%$ drop in efficiency but this reduction could be as high as $20 \%$ to $25 \%$. One case study shows that new motors are not only more energy efficient, but also able to reduce the overall operation cost (CDA, 2003). In addition, this would yield increased reliability. To avoid uncertainties in performance of the motor, a new high efficiency motor can be purchased instead of rewinding one. Several rewind rules are typically used for comparison of motors: (1) never rewind a motor damaged by excessive heat; (2) replace motors that are less than 100 horsepower and more than 15 years old; and (3) replace previously rewound motors.

Adjustable speed drives. ASDs better match speed to load requirements for motor operations. There are various technologies to control the motor. The systems are offered by many suppliers and are available worldwide. Worrell et al. (1997) provide an overview of savings achieved with ASD in a wide array of applications and depended on the flow pattern and loads. The savings may vary between 7 and 60\%. Payback period may vary widely depending on the size of the motor system and use pattern. Case studies of ASDs on cooling tower fans, ventilation equipment have demonstrated payback periods of around 2 years.

Replace Belt Drives. Inventory data suggests 4\% of pumps have V-belt drives, many of which can be replaced with direct couplings to save energy (Xenergy, 1998). Based on assessments in several industries, including wineries, savings are estimated at $4 \%$. Investment costs are estimated at $\$ 0.10 / \mathrm{kWh}$-saved with a simple payback period of 0.7-0.8 years.

\subsection{Lighting}

Lighting is used either to provide overall ambient light throughout the manufacturing storage and office spaces or to provide low bay and task lighting to specific areas. High-intensity discharge (HID) sources are used for manufacturing and storage areas, including metal halide, high-pressure sodium and mercury vapor lamps. Fluorescent, compact fluorescent (CFL) and incandescent lights are typically used for task lighting and offices. In addition, lighting controls should be used in all areas of the plant. ENERGY STAR ${ }^{\circledR}$, a voluntary program developed by the EPA to encourage the 
installation of energy efficient lighting, has suggested cost-effective ways to save on lighting energy (EPA, 2001).

In wineries, the share of electricity for lighting use may vary between 8 and 20\%, depending on the efficiency of the lighting installed, the type of lighting and other electricity uses. In this study we assume that the average winery may use $12 \%$ of all electricity for lighting. Lighting may be subdivided in lighting in warehouses and production facilities, offices and public spaces, and exterior lighting. Note that improved lighting efficiency in cooled spaces will also reduce the cooling demand.

Switch off lights when not occupied. An energy management program that aims to improve the awareness of personnel with regard to energy use can help to switch off lights and other equipment when not in use.

Replace incandescent lights with fluorescent lights or compact fluorescent lights (CFL). The fluorescent lamp lasts roughly ten times longer than an incandescent light and is three times more effective in lighting provided. Typical energy savings are 50$75 \%$ per lamp. The payback period for the replacement varies with the number of hours that the lamps are used, but can be as low as five months. We estimate the typical investments at $\$ 0.20 / \mathrm{kWh}$-saved.

The Benziger family Winery (170,000 cases) replaced incandescent lamps by CFL in 2002, and reduced the total electricity bill for lighting by $25 \%$ (Wine Institute, 2002).

Replace magnetic ballasts with high frequency electronic ballasts. A ballast is a mechanism that regulates the amount of electricity required to start a lighting fixture and maintain a steady output of light. Electronic ballasts save 12-30\% power over their magnetic predecessors (Cook, 1998; EPA, 2001). New electronic ballasts have smooth and silent dimming capabilities, in addition to longer lives (up to $50 \%$ longer), faster run-up times and cooler operation (Eley et al., 1993; Cook, 1998). New ballasts also have automatic switch-off for faulty or end of life lamps.

We assume 25\% typical savings when replacing a magnetic ballast by an electronic ballast. Total energy savings will depend on the number of magnetic ballasts still in use in the winery. Typical energy savings are estimated at $8 \%$ of total electricity use for lighting. The typical investments are estimated at $\$ 0.12 / \mathrm{kWh}$-saved.

Replace T-12 tubes with T-8 tubes. T-12 refers to the diameter in 1/8-inch increments (T-12 means 12/8 inch or $3.8 \mathrm{~cm}$ diameter tubes). The initial output for T-12 lights is high, but energy consumption is also high. They also have extremely poor efficacy, lamp life, lumen depreciation and color rendering index. Because of this, maintenance and energy costs are high. Replacing T-12 lamps with T-8 lamps (smaller diameter) approximately doubles the efficacy of lighting. Also, T-8 tubes generally last $60 \%$ longer than T-12 tubes saving maintenance costs. Typical energy savings from the replacement of a T-12 by a T-8 are around $30 \%$. Based on experiences with several 
industrial facilities, the investment costs for replacing T-12 by T-8 and electronic ballasts are estimated at $\$ 0.25-0.30 / \mathrm{kWh}$-saved.

It is important to remember, however, to work both with the suppliers and manufacturers on the system as a whole through each step of the process. There are a number of T-8 lights and ballasts and the correct combination should be chosen for each system.

The Gillette Company manufacturing facility in Santa Monica, California replaced $4300 \mathrm{~T}-12$ lamps with 496 metal halide lamps in addition to replacing 10 manual switches with 10 daylight switches (EPA, 2001). They reduced electricity by $58 \%$ and saved $\$ 128,608$ annually. The total project cost was $\$ 176,534$, producing a payback period of less than 1.5 years.

Replace standard metal halide HID with high-intensity fluorescent lights. HID lights are typically used in large production spaces and loading docks. Traditional HID lighting can be replaced with high-intensity fluorescent lighting. These new systems incorporate high-efficiency fluorescent lamps (T-5), electronic ballasts and highefficacy fixtures that maximize output to the workspace. Advantages of the new system are many: lower energy consumption, lower lumen depreciation over the lifetime of the lamp, better dimming options, faster start-up and restrike capability, better color rendition, higher pupil lumens ratings and less glare (Martin et al., 2000).

High-intensity fluorescent systems yield 50\% electricity savings over standard metal halide HID. Dimming controls that are impractical in the metal halide HIDs can also save significant energy in the new system. Retrofitted systems cost about \$185 per fixture, including installation costs (Martin et al., 2000). Specific investments are estimated at $\$ 0.16 / \mathrm{kWh}$-saved. In addition to energy savings and better lighting qualities, high-intensity fluorescents can help improve productivity and have reduced maintenance costs.

Replace Mercury Lights by High Pressure Sodium Lights. In industries where color rendition is critical, metal halide lamps save 50\% compared to mercury or fluorescent lamps (Price and Ross, 1989). Where color rendition is not critical, high pressure sodium lamps offer energy savings of 50 to $60 \%$ compared to mercury lamps (Price and Ross, 1989). High pressure sodium and metal halide lamps also produce less heat, reducing HVAC loads. In addition to energy reductions, the metal halide lights provide better lighting, provide better distribution of light across work surfaces, improve color rendition and reduce operating costs (GM, 2001).

Reduce Voltage of HID Lights. Reducing system voltage can also save energy. Toyota put in reduced voltage HID-lights and found a 30\% reduction in lighting (Toyota, 2002). There are commercial products on the market that attach to a central panel switch (controllable by computer) and constrict the flow of electricity to fixtures, thereby reducing voltage and saving energy, with an imperceptible loss of light. 
Voltage controllers work with high intensity discharge (HID) and fluorescent lighting systems. Various systems are on the market, e.g., EnergySaver, Wattman and others.

Energy savings will depend on the number of hours that a light is used. Energy savings will vary between 15 and $35 \%$. We estimate typical energy savings at $15 \%$ of lighting energy use in a winery. The investment costs depend on the size of the lighting system and number of controllers needed. A single voltage controller unit can be used with up to 400 lighting fixtures, depending on the size of the unit and the distance between fixtures. Prices for the units vary, from $\$ 500$ to $\$ 15,000$ (2000 prices), depending on the electrical load. Typical payback for lights that are used 24 hours/day is less than one year. We assume typical costs of $\$ 0.30 / \mathrm{kWh}$-saved.

Exit Signs - Light Emitting Diodes (LEDs). Energy costs can be reduced by switching from incandescent lamps to LEDs or radium strips in exit sign lighting. An incandescent exit sign uses about 40W, while LED-signs may use about 4-8W, reducing electricity use by $80-90 \%$. A 1998 Lighting Research Center survey found that about 80 percent of exit signs being sold use LEDs (LRC, 2001). The lifetime of a LED exit sign is about 10 years, compared to one year for incandescent signs, reducing maintenance costs considerably. In addition to exit signs, LEDs are increasingly being used for path marking and emergency wayfinding systems. Their long life and cool operation allows them to be embedded in plastic materials, which makes them perfect for these applications (LRC, 2001).

A new LED-exit sign costs about \$20-30/piece. Kits are sold to retrofit the lamps in existing exit signs for similar prices. The payback period can be as low as 6 months. EPA's ENERGY STAR program provides a list of suppliers of LED exit signs.

An alternative is the Tritium exit sign that is self-luminous, and do not need any power supply. The lifetime of these signs is estimated at about 10 years, while the costs are $\$ 200 /$ piece or more. The high capital costs make this type of sign attractive for new construction or if no power supply is available.

Lighting controls. Lights can be shut off during non-working hours by automatic controls, such as occupancy sensors, which turn off lights when a space becomes unoccupied. Manual controls can also be used in addition to automatic controls to save additional energy in small areas. Other lighting controls include daylight controls for indoor and outdoor lights, including HID-lights used in loading bays and other production space.

Occupancy sensors can save up to 10 or $20 \%$ of the lighting energy use. Savings are estimated at $2.4 \%$ of total electricity use for lighting at a typical winery facility. Numerous case studies throughout the United States indicate average payback period for lighting controls is approximately 1.1 years. Based on the assessments we estimate the total costs (including installation) at $\$ 0.15 / \mathrm{kWh}$-saved. 
Daylighting. Daylighting is the efficient use of natural light in order to minimize the need for artificial light in buildings. Increasing levels of daylight within rooms can reduce electrical lighting loads by up to $70 \%$ (Caddet, 2001). Unlike conventional skylights, an efficient daylighting system may provide evenly dispersed light without creating heat gains. The reduced heat gains will reduce the need for cooling compared to skylights. Daylighting differs from other energy efficiency measures because its features are integral to the architecture of a building, and so is applied primarily to new buildings and incorporated at the design stage. However, existing buildings can be costeffectively refitted with daylighting systems. Various daylighting systems are available on the market; some of which can be supplied as kits to retrofit an existing building.

Daylighting can be combined with lighting controls to maximize its benefits. Because of its variability, daylighting is almost always combined with artificial lighting to provide the necessary illumination on cloudy days or after dark. Daylighting technologies include properly placed and shaded windows, atria, angular or traditional (flat) rooflights, clerestories, light shelves and light ducts. Clerestories, light shelves and light ducts utilize angles of the sun and redirect light with walls or reflectors.

Not all parts of the winery may be suitable for the application of daylighting. Daylighting is most appropriate for those areas that are used in daytime hours by people. This may include parts of the winery, bottling facility, offices, tasting room and parts of the warehouses. Lighting in office and similar spaces may consume as much as $2 \%$ of total winery electricity use. In office spaces, daylighting may save between 30 and $70 \%$ (Caddet, 2001). The savings will vary widely depending the facility and buildings. As general guidance we estimate the typical savings on $14 \%$ of total lighting electricity use in a typical facility.

Various companies offer daylighting technologies. More information on daylighting can be found at the website of the Daylighting Collaborative led by the Energy Center Wisconsin (http://www.daylighting.org/). Daylighting systems will have a payback period of around 4 years, although shorter paybacks have been achieved. We estimate typical investments at $\$ 0.50 / \mathrm{kWh}$-saved.

\subsection{Hot Water Supply}

Boilers are the heart of the hot water generation system, and substantial efficiency improvements are feasible here. Boilers are also the main fuel user within the winery. Wineries will mainly use hot water for cleaning, heating of tanks for malolactic fermentation, and for preheating wine before bottling or after cold-stabilization. The main efficiency measures are listed below. These measures center on improved process control, reduced heat loss and improved heat recovery. Furthermore, cogeneration (potentially combined with absorption cooling) can offer additional benefits (see below). 
Ozone cleaning barrels. Barrel cleaning consumes around 1.6 gallons of warm water per barrel. Moving to an ozone cleaning system (see water efficiency opportunities) eliminates the use of hot water for barrel cleaning.

The degree of application is selected in the water efficiency sheet. The marginal costs are zero as the costs of the measure have already been accounted with water efficiency.

Improved boiler maintenance. A simple maintenance program to ensure that all components of the boiler are operating at peak performance can result in substantial savings. In the absence of a good maintenance system, the burners and condensate return systems can wear or get out of adjustment. Fouling of the fireside of the boiler tubes or scaling on the waterside of the boiler should also be controlled. These factors can end up costing a steam system up to $20-30 \%$ of initial efficiency over 2-3 years (DOE, 2001a). We estimate a 10\% possible energy savings on average (DOE, 2001a). Improved maintenance may also reduce the emission of criteria air pollutants. Numerous case studies estimate an average payback period for boiler maintenance of approximately 8 months.

Reduce flue gas volume. Often excessive flue gas results from leaks in the boiler and the flue. This reduces the amount of heat transferred to the steam, and increases pumping requirements. These leaks are often easily repaired. Savings amount to $2-5 \%$ of the energy formerly used by the boiler (DOE, 2001b). The payback period is between 1 and 2 years.

Flue gas monitors maintain optimum flame temperature and monitor carbon monoxide (CO), oxygen and smoke, by controlling the amount of inlet air. The oxygen content of the exhaust gas is a combination of excess air (which is deliberately introduced to improve safety or reduce emissions) and air infiltration (air leaking into the boiler). By combining an oxygen monitor with an intake airflow monitor, it is possible to detect even small leaks. A small 1\% air infiltration will result in $20 \%$ higher oxygen readings. A higher $\mathrm{CO}$ or smoke content in the exhaust gas is a sign that there is insufficient air to complete the fuel burning. Using a combination of $\mathrm{CO}$ and oxygen readings, it is possible to optimize the fuel/air mixture for high flame temperature (and thus the best energy efficiency) and lower air pollutant emissions. We assume that this measure can be applied to large boilers only because small boilers will not make up the initial capital cost as easily.

Reduce excess inlet air. The more air is used to burn the fuel, the more heat is wasted in heating this air rather than in producing steam. Air slightly in excess of the ideal stoichiometric fuel/air ratio is required for safety, and to reduce $\mathrm{NO}_{\mathrm{x}}$ emissions, but approximately $15 \%$ is adequate (DOE, 2001a; Ganapathy, 1994). Poorly maintained boilers can have up to $140 \%$ excess air, but this is rare. Reducing this boiler back down to $15 \%$ even without continuous automatic monitoring would save $8 \%$ of total fuel use. The vast majority of boilers already operate at $15 \%$ excess air or lower, and thus this measure is not considered significant (Zeitz, 1997). However, if the boiler is using excess air, numerous case studies indicate an average payback period for this measure 
of 8 months. A rule of thumb often used is that boiler efficiency can be increased by $1 \%$ for each $15 \%$ reduction in excess air or $40^{\circ} \mathrm{F}\left(22^{\circ} \mathrm{C}\right)$ reduction in stack gas temperature (DOE, 2001a). CIPEC (2001) estimates reducing oxygen $\left(\mathrm{O}_{2}\right)$ in the flue gas by $1 \%$ increases boiler efficiency by $2.5 \%$.

Correct sizing of boiler. Correctly designing the boiler system at the proper steam pressure can save energy by reducing stack temperature, reducing piping radiation losses and reducing leaks in traps and other sources. In a study done in Canada on 30 boiler plants, savings from this measure ranged from $3 \%$ to $8 \%$ of the total gas consumption (Griffin, 2000). Savings were greatest when the pressure is reduced below 70 psig.

If hot water demand varies widely over time, it may be beneficial to 'cascade' a number of smaller boilers. With increasing hot water demand, more boilers will run. The advantage is that the boilers will always run near its peak efficiency at full load. Cascading boiler systems, using multiple boilers sized for domestic applications, are used by commercial facilities in The Netherlands and Belgium These systems result in reduced purchase costs (due the purchase of a mass-produced boiler), reduced need for spare capacity, as well as reduced operation costs. These systems are only applicable to small wineries, and need to be properly designed and operated by a computerized energy management system.

The energy savings for properly sizing of boilers is estimated at $8 \%$ of boiler fuel use. The payback period will depend strongly on the size and age of the existing boiler(s), as well as fuel prices. For calculation purposes we assume a payback period of 3 years. Only a detailed assessment of the specific boiler(s) will provide a more correct cost estimate.

Improve insulation of boiler. It is possible to use new materials that insulate better, and have a lower heat capacity (and thus warm up faster). Savings of $6-26 \%$ can be achieved if this improved insulation is combined with improved heater circuit controls. Improved control is required to maintain the output temperature range of the old firebrick system. Because of the ceramic fiber's lower heat capacity, the output temperature is more vulnerable to temperature fluctuations in the heating elements (Caffal, 1995). An additional benefit is that heating is more rapid when starting the boiler. Several case studies estimate an average payback period for this measure of about 1 year.

Solar Water Heating. A solar boiler uses solar energy to (pre-) heat the water in a solar collector. Solar boilers have mainly been designed for small-scale household applications or to heat pools. However, for small wineries a solar boiler may be a good alternative. The harvesting season sees a major part of the water use for cleaning (excluding year-round operation of a bottling facility), and this is also a time with large availability of sunlight. A solar boiler may reduce the costs of hot water supply by up to $40-80 \%$, strongly depending on the current hot water supply. Electric water heating is typically the most expensive option, followed by propane-fired systems, while natural 
gas is typically the cheapest hot water supply option. Most wineries will use natural gas as fuel for the hot water supply, which will limit the profitability of installing a solar water heater. For those systems, we estimate a payback period of 8 years. For electric systems the payback period may be as low as 2-4 years. A solar hot water system needs to be optimized for the specific location and application. Only an onsite assessment can provide a better estimate of the savings and profitability. When considering a solar water heater, a specialized contractor should be hired to advise on the installation specifications.

Return condensate. Reusing the hot condensate in the boiler saves energy, reduces the need for treated boiler feed water and reclaims sensible heat savings. Usually fresh water must be treated to remove solids that might accumulate in the boiler, and returning condensate can substantially reduce the amount of purchased chemical required to accomplish this treatment. The fact that this measure can save substantial energy costs and purchased chemicals costs makes building a return piping system attractive. We assume a 10\% energy savings and found an average payback period of about 1.1 years.

Re-locate boiler to most efficient location. Transport of hot water will lead to energy losses in the piping. While energy losses can be reduced (see below) the location of the boiler near the major hot water uses (e.g. bottling line, malolactic fermentation tanks) would minimize the transport losses. Assuming a well-maintained hot water distribution network the savings by minimization of transport distance are estimated at $5 \%$. The costs will strongly depend on the local conditions and layout of the winery. We assume a payback period of 3 years.

Repair leaks in distribution piping. Distribution pipes themselves often have leaks that go unnoticed without a program of regular inspection and maintenance. In addition to saving 3\% of energy costs, having such a program can reduce the likelihood of having to repair major leaks, thus saving even more in the long term (DOE, 2001a). Average payback period from several case studies is estimated at about 4 months.

Maintain insulation hot water piping. It is often found that after heat distribution systems have undergone some form of repair, the insulation is not replaced. In addition, some types of insulation can become brittle or rot under normal wear. As a result, a regular inspection and maintenance system for insulation can save energy (Zeitz, 1997). Exact energy savings and payback periods are unknown and vary based on the existing practices.

Insulate Hot Water Distribution Pipes. Using more insulating material or using the best insulation material for the application can save energy in hot water and steam systems. Crucial factors in choosing insulating material include low thermal conductivity, dimensional stability under temperature change, resistance to water absorption and resistance to combustion. Other characteristics of insulating material may also be important depending on the application. These characteristics include tolerance of large temperature variation and system vibration and compressive strength 
where insulation is load bearing (Baen and Barth, 1994). Improving the insulation on the existing U.S. stock of heat distribution systems would save an average of $3-13 \%$ in all systems (DOE, 2001a). CIPEC (2001) estimates that insulating a 10 foot long 4 inch steam pipe can be paid back in less than 6 months. For hot water systems we estimate the payback period at 1 year.

Heat exchanger replaces tank water heating. After wines are done fermenting, wines are generally heated to 50 to 54 degrees $\mathrm{F}$ for bottling (so that the labels stick). For wineries that do on-site bottling, using a heat exchanger in the pre-bottling area more efficiently warms the wine while reducing water consumption and lowering maintenance costs. Fetzer Vineyards installed a heat exchanger in its winery and found energy savings of $69 \%$.

\subsection{Other Measures - Fuel}

Weekend setback temperatures. Setting building temperatures lower during the winter or higher during the summer over the weekend and during non-production times for appropriate buildings (e.g. office buildings during the weekend) can save energy by reducing heating or cooling needs. Hundreds of case studies in the IAC database (2002) estimate costs to be very small. Averaging the IAC case studies shows typical investment per MBtu saved to be just over $\$ 1$.

\subsection{Other Measures - Electricity}

Energy Management Systems. Changing how energy is managed by implementing an organization-wide energy management program is one of the most successful and costeffective ways to bring about energy efficiency improvements.

An energy management program creates a foundation for positive change and provides guidance for managing energy throughout an organization. In companies without a clear program in place, opportunities for improvement may be known but may not be promoted or implemented because of organizational barriers. A successful program in energy management begins with a strong commitment to continuous improvement of energy efficiency. This involves assigning oversight and management duties to an energy director, establishing an energy policy, and creating a cross-functional energy team. Steps and procedures are then put in place to assess performance, through regular reviews of energy data, technical assessments and benchmarking. From this assessment, an organization is able to develop a baseline of energy use and set goals for improvement. Performance goals help to shape the development and implementation of an action plan. An important aspect for ensuring the successes of the action plan is involving personnel throughout the organization. Personnel at all levels should be aware of energy use and goals for efficiency. Staff should be trained in both skills and general approaches to energy efficiency in day-to-day practices. In addition, 
performance results should be regularly evaluated and communicated to all personnel, recognizing high achievement.

Evaluating performance involves the regular review of both energy use data and the activities carried out as part of the action plan. Information gathered during the formal review process helps in setting new performance goals and action plans and in revealing best practices. Establishing a strong communications program and seeking recognition for accomplishments are also critical steps. Strong communication and receiving recognition help to build support and momentum for future activities.

The potential savings achieved through an energy management system vary widely. Conservatively, we assume that winery-wide savings of $3 \%$ are possible through increased attention (besides the potential savings from specific measures described elsewhere).

Efficient Transformers. Wineries may have various transformers onsite to produce low voltage. Transformers may have losses equivalent up to $3 \%$. By replacing the transformers by more energy efficient models, energy losses can be reduced by roughly $30 \%$ (depending on the typical load of the specific transformer). The ENERGY STAR program has labeled various efficient transformer models (see also www.energystar.gov). The ENERGY STAR transformers demonstrate lower losses at various load levels. The payback period based on the marginal costs of installing an efficient transformer is generally less than 1-2 years (Fetters, 2002).

Power Factor Correction Systems. Computers, variable speed drives, welding arcs and other equipment can lead to poor power quality. The distortion of the harmonics can lead to an increased energy bill and reduced efficiency (through increased generation of heat) while heavily distorted harmonics may damage equipment. The losses may vary widely from one site to another, depending on the electricity end uses and maintenance of the equipment. We assume that on average the losses are in the order of 2-3\%. Installing power factor management (or filters) may reduce these losses. The payback period of installing harmonic filters depends on the capacity, and may vary between 12 and 18 months. We conservatively assume a payback period of 18 months. Alternatively, when purchasing equipment, compliance with IEEE Standard 519 is important (see http://www.ieee.org/portal/site for more information).

Power Management Office Equipment. Office equipment (e.g. computers, copiers), while small in a winery, are often left on overnight or during periods that they are not used. ENERGY STAR office equipment has power management software to turn off (or down) equipment after a set period of time. However, often this is not properly installed. Surveys of after-hours use of equipment have found that generally $50 \%$ of the computers in small businesses is not turned off or down (Roberson et al, 2004). A monitor turned down uses only $10 \%$ of the energy of a monitor without power management options installed. Properly installing the software or controls may lead to savings of $50 \%$ or more (assuming 10 hours of use/day, and going to sleep mode). 
Furthermore, turning equipment off manually may lead to additional savings (up to 10\%). This has been covered by the measure Energy Management Systems.

Electronic Controls to Turn Off Equipment. Electronic controls can be as simple as on/off switches to be switched off during non-operating hours. According to the IAC database (2002), implementation costs range from $\$ 150$ for simple controls to almost $\$ 3000$ for industry specific controls on industrial equipment and HVAC. We assume an average cost of implementation from all of the case studies in the IAC database affecting electricity use, likely a conservative estimate for simple HVAC controls.

Waste Water Treatment - Anaerobic Digestion. Generally, winery wastewater is aerobically treated in ponds, using a considerable amount of electricity for aeration. After many years of research and experimentation worldwide, technologies have been developed that allow anaerobic digestion of winery wastes. Various wineries in France, South Africa, Australia and the U.S. use the technology to treat wastewater.

In the U.S., the Canandaigua Winery (New York) has installed the first anaerobic digestion system in 1997, and since then expanded the system. The system reduced electricity consumption for wastewater treatment by approximately 7,160 kWh/day, or $68 \%$ compared to the previously used aerobic pond system. The biogas generated in the digester is used to heat the digester. Excess gas could be used for power generation. Furthermore, the system resulted in reduced costs for sludge disposal, due to the reduced sludge volume (Quinn, 2002). This has resulted in a cost reduction for wastewater treatment of $\$ 0.03 /$ case.

Investment costs for an anaerobic digestion system are relatively high, but the benefits may warrant the investments. Typically, the payback period of anaerobic digesters in agriculture is between 3 and 7 years based on experiences of the AgStar program (AgStar, 2004). The investments for the Canandaigua Winery were not available, as the project was financed by the technology provider (now called Ecovation, Inc.).

Photovoltaics. Photovoltaic (PV) cells directly generate electricity from solar light. Although the technology is still expensive (but coming down in price continuously), PV generates power during the peak of demand (e.g. during the crush, and the middle of the day). This reduces peak demand and may offset high power rates. Furthermore, PV systems do not generate any emissions, last for 20 years or longer, have no movable parts, and require little maintenance. PV systems are generally installed as rooftop systems, so that they do not use any additional space. A number of wineries (e.g. Fetzer Vineyards (41 kW), Ridge Vineyards (65 kW), St. Francis (457 kW), Rodney Strong (766 kW), Domaine Carneros (120 kW) and Mount Eden (20 kW)) have installed PV-systems. The PV systems not only reduce electricity demand, they contribute to sustainable development of the winery and a positive public image.

Various suppliers in California can supply and install PV systems (e.g. Powerlight, Akeena, Premier Power, Renewable Technologies, Inc.). 
PG\&E and other utilities provide rebates for installing PV systems, while California regulation allows net metering of PV-generated electricity (i.e. power generated from a PV system can be fed to the grid against the full purchase price of the electricity).

\subsection{Combined Heat and Power Production (CHP)}

Cogeneration is a viable option for many wineries. The existence of simultaneous power, heating (hot water) and cooling loads make cogeneration an attractive option. A cogeneration system consists of a prime mover and heat recovery equipment. The use of adsorption or absorption coolers allows the use the generated heat to be used for cooling. For most wineries the suitable prime movers are the more traditional reciprocating engines and more advanced microturbines.

Reciprocating engines (e.g., diesel engines) convert fuel to shaft power, which then spins a generator. Diesel generators have long been used to generate small amounts of electricity at industrial, commercial, and institutional sites, either for continuous use or for backup in case of utility power failure. Reciprocating engines are the dominant independent generation technology for small installations, accounting for $47 \%$ of sites but only $2 \%$ of the power generation. This type of system is most commonly found in the food products industry.

Traditionally, engines needed a lot of maintenance, had less reliability, and could potentially emit relatively large amounts of NOx. Recent developments in engine design have increased power efficiency and reliability, while dramatically reducing the emissions of these engines. These new designs can use a variety of liquid and gas fuels, including natural gas. For emissions reasons, natural gas-fired engines have become dominant for continuous operation applications (i.e., not emergency generators). The electric efficiency of gas engines varies from 30-37\% (HHV), with larger engines having the higher efficiency. Total system efficiencies for cogeneration applications vary between $69 \%$ and $78 \%$ (Goldstein et al., 2003).

Microturbines are a new class of small combustion turbine engines, ranging in size from $25 \mathrm{~kW}$ to $500 \mathrm{~kW}$ of electric generating capacity. Like the current class of industrial turbines, which were developed using jet engines as a model, these devices are derived from several types of turbo-machinery, including aircraft auxiliary power units and industrial gas compressors. Like their larger siblings, microturbines can run on a variety of liquid and gaseous fuels, with natural gas projected to be the most common. They come in several physical configurations, which represent tradeoffs in cost and performance. Simple-cycle microturbines (used for power generation alone) have an efficiency of 23-26\%, HHV (Goldstein et al., 2003). When used in a cogeneration or combined heat and power (CHP) system, the fuel conversion efficiency exceeds $60 \%$ (Goldstein et al., 2003). The leading domestic suppliers of micro turbines are Capstone and Ingersoll-Rand, and a few European (e.g., Bowman) and Japanese manufacturers (e.g., Mitsubishi, Toyota) also supply the U.S. market.

Table 5 provides an overview of typical characteristics and performance indicators for small-scale cogeneration systems. 
Table 5. Technical and Economic Characteristics of small-scale cogeneration technologies Source: Goldstein et al., 2003.

\begin{tabular}{|l|l|l|l|l|}
\hline & \multicolumn{2}{|c|}{ Reciprocating Engines } & \multicolumn{2}{c|}{ Microturbines } \\
\hline Electric capacity $(\mathrm{kW})$ & 100 & 300 & 30 & 100 \\
\hline Heat production $(\mathrm{kW})$ & 164 & 445 & 54 & 136 \\
\hline Power/heat ratio & 0.61 & 0.67 & 0.52 & 0.62 \\
\hline $\begin{array}{l}\text { Fuel equivalent of } \\
\text { electricity (Btu/kWh, } \\
\text { HHV) }\end{array}$ & 11,500 & 10,967 & 15,071 & 13,127 \\
\hline $\begin{array}{l}\text { Electrical Efficiency (\%, } \\
\text { HHV) }\end{array}$ & 30 & 31 & 25.1 & 26.0 \\
\hline $\begin{array}{l}\text { Total CHP efficiency (\%, } \\
\text { HHV) }\end{array}$ & 78 & 77 & 67 & 62 \\
\hline Net Heat rate (Btu/kWh) & 4,500 & 4,641 & 6,795 & 7,300 \\
\hline Installed Costs $(\$ / \mathrm{kW})$ & 1,350 & 1,160 & 2,636 & 1,769 \\
\hline O\&M Costs $(\$ \mathrm{kWh})$ & 0.018 & 0.013 & 0.02 & 0.015 \\
\hline $\begin{array}{l}\text { Average costs of power } \\
\text { produced }(\$ / \mathrm{kWh})\end{array}$ & 0.068 & 0.059 & 0.098 & 0.086 \\
\hline
\end{tabular}

Note: The average cost of power production will depend strongly on the natural gas price. The values in the table are based on a natural gas price of \$3.97/MMBtu (2003).

A cogeneration system should be optimized based on the demand for cooling and heating. A careful analysis of energy consumption data for a number of years is necessary to scale the system to the needs of the site. Generally, the system will be designed to meet the baseload, while peak demand during the crush (for fermentation) will be met with additional cooling equipment.

Adsorption/absorption cooling is a technology to use the recovered heat from the cogeneration unit to provide cooling. The cooling can be used for fermentation tanks, and for other parts of the winery depending on demand. In absorption refrigeration cycle, vapor compression is dispensed by dissolving the low pressure vapor in a liquid, pumping the solution to high pressure and generating high pressure vapor by heating the high pressure solution. Ammonia/water is most common vapor/liquid solution. Typically it requires waste heat at about $250 \mathrm{~F}$ or higher to drive the system. Absorption coolers are produced by a number of suppliers (e.g. Carrier, York, Trane, Robur, McQuay, LG Machinery, and Century). Absorption coolers can be found in different wineries and at varying scales. E. and J. Gallo uses a 500 ton absorption chiller at its Modesto facility for the cooling of stored wine.

In contrast, adsorption cooling utilizes the capacity of certain substances to adsorb water on their surface, from where it can be separated again with the application of heat. Adsorption units use hot water from the cogeneration unit. It can be driven by lower temperatures, typically around $200 \mathrm{~F}$. These systems do not use ammonia or corrosive salts, but use silica gel, reducing maintenance. Adsorption units were originally developed in Japan (by e.g. Mycom and Nishiyodo Kuchou) and are now also marketed in the U.S. (by HIJC USA, Houston, TX). Four industrial sites in California use this technology (see also below), while it has a proven track record in Japan and selected sites in Europe. 
The thermal performance of both systems is similar with a COP (coefficient of performance) between 0.68 and 0.75 , and capital costs are comparable. However, the reliability of an adsorption unit is expected to be better, and maintenance cost is expected to be lower.

In 2003, Vineyard 29 in Napa installed two $120 \mathrm{~kW}$ microturbines (Capstone C60) to supply power to the winery, hot water and cooling. The cooling is provided by an adsorption unit using the hot water generated by the micro turbines. The system is sized to meet the baseload heating and cooling needs. Extra cooling needed during fermentation is provided by a traditional cooling system. The system allows a reduction of electricity demand during the summer peak, reducing the electricity rates for the winery. Vineyard 29 received financial support for the cogeneration system from the utilities. The investments are around $\$ 400,000$. A rebate of $\$ 200,000$ reduced the payback period of the system to an estimated at 2-3 years (Coggan, 2004). 


\section{Water Efficiency Opportunities}

\subsection{General Water Measures}

Water Management Plan. Like energy efficiency, we expect changing how water is managed by implementing an organization-wide water management program to be one of the most successful and cost-effective ways to bring about water efficiency improvements.

A water management program creates a foundation for positive change and provides guidance for managing water throughout an organization. In companies without a clear program in place, opportunities for improvement may be known but may not be promoted or implemented because of organizational barriers. A successful program will have a water managing director and/or a water efficiency team, promoting water efficiency within the winery. Water should be metered and performance monitored. Performance should be assessed regularly through reviews of the data, technical assessments and benchmarking. Performance goals should also be set. Personnel throughout the winery should be aware of water use and goals for efficiency.

North Carolina's Department of Environment and Natural Resources Division of Pollution Prevention and Environmental Assistance (2005) outlines 6 steps to a successful water efficiency program:

1. Establish commitment and goals

2. Line up support and resources

3. Conduct a water audit

4. Identify water management options

5. Prepare a plan and implement schedule

6. Track results and publicize success.

According to California Sustainable Winegrowing Alliance, of wineries that have implemented a comprehensive water conservation program, monitored and recorded total use, set yearly goals and set up a water team, about $1 / 3$ found savings of $15 \%$ and $2 / 3$ found savings of $10 \%$ (CSWA, 2004). We conservatively assume a $5 \%$ savings for any winery that sets up a water conservation program, assuming most wineries have implemented some conservation measures already and not all savings will be realized immediately.

Repair Leaks. Facilities require ongoing leak detection and repairs if they are to maintain water efficiency. Leak detection should include all water uses and connections, including meters, water distribution lines, piping and connections for fixtures, appliances, process water, cooling water, hot water and landscaping. We assume repairing leaks applies to all water used, and do not split up this measure among the different processes. We leave this up to the user in the application potential box (column B in the WE-Water Sheet in BEST Winery). 
A variety of leak detection equipment is available, including leak detection services, water test flow kits (about \$600-\$1100) and portable metering devices (about \$700$\$ 1100)$. Generally, the costs per gallon saved are negligible.

\subsection{General Cleaning}

Sweeping floors before water washing. Sweeping floors of large solid debris before washing with water will save water. We estimate a $20 \%$ savings of water used for washing floors in the crush pad, barrel room and bottling facilities. We assume $10 \%$ of the water used in those areas is for cleaning surfaces that could be swept. Costs are negligible (brooms, potentially slightly longer labor hours) compared to the cost of the gallons of water saved for this measure.

High Pressure nozzles with automatic shutoff devices. Installing high pressure nozzles with automatic shutoff devices can reduce water use by limiting water use from the hoses used for cleaning. According to Vickers (2001), these nozzles cost between $\$ 10$ to $\$ 25$ per nozzle, and savings can be as much as $40 \%$. We assume savings of $40 \%$ that applies to $80 \%$ of the water used in the winery, crush pad, and storage areas, $10 \%$ of the water used in the barrel rooms, and $10 \%$ of the water used in bottling.

\subsection{Barrel Cleaning}

High pressure nozzle - tank cleaning. High pressure nozzles can provide more precise cleaning in a shorter time, using less water in the process. One model by Gamajet uses as little as 8 GPM for 1.5 minutes, cleaning a whole barrel with just 12 gallons of water. Compare this with a typical sprayball which uses 25 gallons per barrel. We estimate savings to be about $40 \%$ of all water used in barrel cleaning. We estimate about $80 \%$ of the water used in the barrel room is used to wash barrels, and $10 \%$ is used for floors and other cleaning (and 10\% is for humidifiers). Gamajet costs $\$ 2,200$ for their high pressure barrel washers. Multiple high pressure nozzles will be needed for wineries with more than one nozzle per tank cleaning line.

Ozone tank cleaning of barrels. Ozone cleaning can eliminate the need for hot water use for barrel cleaning, reducing water use by $50 \%$. We estimate typical water use for barrel cleaning at 1.6 gallon/case. Various suppliers provide (mobile) ozone generators. Ozone is a toxic gas. It is made onsite and on demand by a generator. This eliminates the risks of storage. Personnel using the ozone cleaning process should be properly trained.

Automatic cleaning systems. Automatic cleaning systems can combine high pressure and hot water in an automated system, reducing water use by as much as $80 \%$ compared to un-automated spray balls. Gamajet sells automated systems beginning at $\$ 9650$. Other systems are produced by Tom Beard and Process Engineers and sell for 
about $\$ 26,000$ to 27,000 . We assume a typical two-barrel system will cost about $\$ 20,000$ and will save $50 \%$ of water used in barrel washing.

\subsection{Cooling Tower}

Alternative sources of make-up water. Wineries that can reuse water from another process should consider using it in cooling make-up water. Water that is treated on site might be suitable for make-up water, though water softening treatment may be necessary to avoid phosphate scale buildup. One large project in the Netherlands set up a system amongst 9 companies, reusing process water for cooling water (European Environmental Press, 2000). They found costs of about 0.0015 Euros (or 0.00142000 U.S. \$) per gallon saved with a payback of about 4 months. These costs are an estimate as actual costs will vary depending on how much additional treatment is required, if any, and what kind of piping is needed to supply the cooling water.

Replace single pass cooling system with cooling tower. As the name implies, oncethrough cooling systems use water once and dispose of it. Conversely, cooling towers recycle water within the tower, saving 90 to $95 \%$ of the water used in single pass systems. A hospital replaced their single pass systems with cooling towers for $\$ 5,500$ and found savings of 2.1 million gallons per year. Similarly, an ink manufacturer replaced its single pass system and found $80 \%$ savings. We used these studies to estimate costs of water saved, and estimated savings to be $90 \%$ of all cooling water used in single pass systems (Vickers, 2001).

Reduce bleed off in cooling tower. By allowing higher concentrations of suspended and dissolved solids in the circulating water, bleed-off in the cooling tower is reduced, saving water. Of course, required quality regulations must be maintained. Adjusting the physical or chemical treatment of circulating water increases the cycles of concentration. The goal is to achieve the maximum number of cycles without forming scales. A reasonable goal in most cases is to achieve at least six cycles of concentration. Typical concentration ratios are two to three (North Carolina Department of Environment and Natural Resources Division of Pollution Prevention and Environmental Assistance, 2004). We conservatively assume most wineries that have not implemented this measure will begin at a concentration cycle of three. Typical savings achieved by increasing concentration cycles from 3 to 6 are about $20 \%$. (Savings achieved by increasing cycles from 2 to 6 are $40 \%$ ).

The Ventura Coastal Plant which processes citrus fruit increased the concentration ratio of its cooling towers and evaporative coolers to 5, reducing bleed-off by $50 \%$ and saving almost 5,200 gallons per day (Department of Water Resources, California, 2004), with capital costs of $\$ 5,000$, the payback period is about 7 months.

Operate bleed off continuously/install controls. Cooling towers are usually bled off automatically in batches when the mineral concentration or conductivity reaches a 
certain level (Vickers, 2001). The batch method can result in wide fluctuations in bleedoff volumes without proper controls. Operating the cooling tower on a continuous basis to maintain conductivity can minimize water use during bleed-off. According to North Carolina's Department of Environment and Natural Resources Division of Pollution Prevention and Environmental Assistance, installing controls can help achieve optimal bleed-off. Submeters can be installed on most cooling towers for less than $\$ 1000$. We assume a $5 \%$ reduction in cooling water requirements by implementing this measure.

\subsection{Evaporative Cooling}

Replace non-recirculating evaporative coolers. Similar to cooling towers, oncethrough evaporative coolers use water only once and dispose of it. Conversely, recirculating evaporative coolers recycle water saving $70 \%$ of the water used in single pass evaporative coolers. Air cooled units save even more water.

A hospital installed a recirculating cooling water system and found savings of 8.5 million gallons per year. Purchase and installation costs were $\$ 19,500$ and savings totaled \$55,685 per year, yielding a 4-month payback (Vickers, 2001). We used this study to estimate costs of water saved, and estimate savings to be about $70 \%$ of all cooling water used in once-through systems.

Reuse bleed-off water in evaporative cooling. Like the cooling tower, bleed-off water in evaporative cooling should be minimized while maintaining discharge standards. We assume costs and savings similar to those for the cooling tower.

\subsection{Hot Water}

Reduction of make-up water by reduction in energy use. Reducing the overall hot water requirements in the boiler not only saves energy but also reduces the need for treated boiler feed water. Usually fresh water must be treated to remove solids that might accumulate in the boiler, so this measure can substantially reduce the amount of purchased chemicals required to accomplish this treatment, as well as the amount of water needed. The fact that this measure can save substantial energy costs, water costs and purchased chemicals costs makes reducing make-up water a particularly attractive measure.

The degree of application is coupled to the measures on the energy efficiency sheet EEhot water, hot water measures for energy efficiency. The marginal costs for reduction of water use are assumed to be zero, as all costs are assigned to hot water energy efficiency measures. The amount of water savings is also linked the amount of energy saved, already calculated on the EE-hot water sheet.

Return Condensate/Used Water. Reusing the hot condensate in the boiler saves energy, reduces the need for treated boiler feed water and reclaims sensible heat 
savings. Usually fresh water must be treated to remove solids that might accumulate in the boiler, and returning condensate can substantially reduce the amount of purchased chemical required to accomplish this treatment, as well as the amount of water needed. The fact that this measure can save substantial energy costs, water costs and purchased chemicals costs makes building a return piping system attractive.

The degree of application is coupled to the return condensate measure in the sheet on EE-hot water, hot water measures for energy efficiency. The marginal costs for reduction of water use are assumed to be zero, as all costs are assigned to hot water energy efficiency measures. We assume a $20 \%$ savings of hot water is possible by returning condensate.

\subsection{Humidifiers}

Controls and water supply valves. We assume a $10 \%$ savings in water due to controls and water supply valves. We also assume about $10 \%$ of the water used in the barrel rooms is used for humidification. TrueFog, USA manufactures complete control systems for $\$ 3290$.

Efficient humidifier models. Low flow but better dispersive models can save water in humidification. We assume $10 \%$ of the water used in the barrel room is used for humidifiers, and that $50 \%$ of this can be saved by installing more efficient humidifier models. Efficient humidifier models should include adjustable water supply valves to control water flow.

Caves for barrel storage. The typical loss due to evaporation from the barrel in Northern California is around 4 gallons per barrel/year (Lewis and Leech, 2004). Caves maintain a constant humidity of $70-90 \%$, and hence reduce the need for humidification for barrel storage. The degree of application is coupled to the area for which a cave is constructed as defined in the section on refrigeration measures. The marginal costs for reduction of water use are assumed to be zero, as all costs are assigned to refrigeration.

\subsection{Miscellaneous}

Efficient toilets and building appliances. Standard toilets use 3.5 gpf. Water efficient (low-flow) designs use only 1.6 gpf. Studies have shown that water use is reduced by $19 \%$ on average due to low-flow toilets (http://www.epa.gov/owm/waterefficiency/toilets.htm). Experiences in various cities have demonstrated of these measures have payback periods of about 1 year. We assume similar characteristics for other water efficiency measures, not used directly in the production process. 


\title{
9. Instructions and Tool Documentation
}

BEST Winery allows you to evaluate the energy and water efficiency of a winery by benchmarking energy and water intensity against an efficient reference winery. The reference winery is based on existing and proven practices and technologies. The reference winery simulates the production of the same products using the characteristics that you enter for your winery, however, using the most efficient technology. This will provide a score, called the Energy Intensity Index (EII) or Water Intensity Index (WII), which is a relative indication of the performance of the winery.

After evaluating the performance of the winery, you can evaluate the impact of selected energy-and water-efficiency measures by choosing the measures that you would likely introduce in the winery, or would like to evaluate for potential use. You select the degree or share of implementation for each of the measures, and BEST Winery will calculate the overall energy and water savings, cost savings, payback period and a recalculated EII and WII.

\begin{abstract}
Applicability
BEST Winery is designed for wineries that produce most wines (except for Champagne-like wines) and that have the tanks and barrels inside a building. Wineries that operate large outdoor tanks cannot use BEST Winery to evaluate the performance of the winery. Most wineries in California use indoor tanks.
\end{abstract}

\section{Computer Requirements}

BEST Winery is designed for use in Excel using a PC with Windows 2000 or Windows XP.

After entering data please save BEST Winery with a different file name on your computer.

\section{Using BEST Winery - step-by-step}

An Excel workbook consists of a number of worksheets. Data from the input sheets is used for calculations throughout the workbook. After completing a worksheet, the user will be automatically transferred to the next worksheet by pressing a button on the worksheet. In the following, we walk through the worksheets of BEST Winery step-bystep.

\section{Input Sheet}

In the Input Sheet you enter all essential information to enable benchmarking of your winery. BEST Winery assumes standard industry practices for fermentation and other process steps. If you wish to change these to simulate the practices at your winery, you must also fill in the worksheet "Optional Input".

Only fill in the yellow cells! Cells with other colors are calculated from input data. 
1. In the input sheet you first need to select the region where your winery is located and the region from which you source most of your grapes.

2. Secondly, you need to enter the annual production volumes of the different production steps in the winery, i.e. grapes received, juice received, total juice fermented, wine undergoing malolactic fermentation, amount of wine that is cold stabilized, amount of wine stored, total wine production, and total number of cases bottled onsite. BEST Winery distinguishes four types of wine, i.e. red, tank fermented dry whites, tank fermented sweet whites and barrel fermented white wine. Note that the unit for production volumes varies with the production step. Also note that the input is for a 12 month period. Wine stored should be based on capacity utilized on average throughout the 12 months, not the entire capacity of your storage rooms. There is a separate optional inventory sheet within the Input Worksheet that can help you calculate the amount of wine stored. (The numbers calculated will then have to be entered into cells C28 and F28, by you, separately).

3. Fill in the energy consumption separately for each fuel and electricity, as well as water. You also need to fill in the energy and water costs. Please fill these in for a full calendar year (12 months).

4. Two final boxes within the water data are required. Choose whether or not you treat your own wastewater onsite and whether or not you pump water from your own wells onsite. Answer yes or no from the drop-down menu.

5. When you filled in all the cells, press the "continue” button.

\section{Optional Input}

The Optional Input sheet allows you to tailor the production process of the reference winery to the production process of your winery. The sheet already contains default values, equal to values typical in most wineries. If you do not change the values in the yellow cells, the model will automatically use these values. If these values reflect or are close to your operating practices, there is no need to change them. If they do not, enter new numbers in the appropriate cells.

Only fill in the yellow cells! Cells in other colors are calculated from input data.

The table follows the production process of the winery, and allows you to change the data to reflect the operating conditions of your winery:

1. Enter the number of days and average number of hours/day that the receiving equipment is running.

2. Enter the number of days and average number of hours/day that the presses are running.

3. Enter the parameters of the building containing the fermentation tanks. Only enter the sizes of the cooled buildings. Please enter the sizes of the buildings/rooms for each of the wine types, or divide the space up over the wines if not processed in separate rooms or buildings. This information is used to calculate the cooling load of the building. The default value is based 
on a typical layout and tank distribution of a winery using tanks with approximately a $10 \mathrm{ft}$ diameter and $18 \mathrm{ft}$. height.

4. For each wine type, enter the typical fermentation conditions, including fermentation temperature, fermentation time, sugar content of the juice, air exchange rate in the building (to remove $\mathrm{CO}_{2}$ ), as well as average tank dimensions.

5. For each wine type, enter the typical malolactic fermentation conditions. These are broken down into wines treated in tanks and those that undergo malolactic fermentation in barrels. Only barrel fermented white wines are assumed to undergo malolactic fermentation in the barrel. Other wines are assumed to undergo malolactic fermentation in tanks.

For tank fermented wines, enter: fermentation temperature, fermentation time, and average tank dimensions.

For barrel fermented wines, enter: fermentation temperature, fermentation time, and dimensions of the barrel room(s).

6. Cold stabilization is another key process demanding refrigeration. For each of the wine types, enter the typical stabilization conditions, including stabilization temperature, stabilization time, share of jacketed tanks, and tank dimensions.

7. Fill in the number of days that each type of wine undergoes fining.

8. For aging and storing in barrels, enter the room temperature at which the wine is stored in the cellar, as well as the cellar/barrel room dimensions. Fill in the temperatures for each of the barrel rooms/wine type. Enter the exchange rate if different than 1.

9. If you have a bottling plant (permanent or mobile), enter the number of weeks that the bottling line is run, and the number of hours per week it is typically in operation (on average).

10. By pressing on the button "Continue", BEST Winery will calculate the energy and water intensity of the winery and compare these to the benchmark values. BEST Winery will open the results sheet.

\section{Results}

The results page will show the Energy Intensity Index (EII) and Water Intensity Index (WII). Once the actual energy intensity and benchmark energy intensity have been calculated for each winery, they can be used to construct an EII (and, similarly, a WII). The EII is a measurement of the total production energy intensity of a winery compared to a benchmark energy intensity. The EII can be used to calculate the energy-efficiency potential at a winery and it can be used for evaluating winery progress in energy efficiency improvement, by eliminating the effects of a change in product mix. The same applies to the WII and water.

The EII and WII can be used to calculate winery efficiency potential by comparing actual winery intensity to the intensity that would result if the winery used "reference" technology for each process step. The difference between the actual intensity, which is the energy and water use per barrel or case produced, and that of the reference or benchmark technology, is calculated for each of the key process steps of the winery and 
then aggregated for the entire winery. The aggregated EII (and WII) is calculated as follows:

$$
E I I=100 * \frac{\sum_{i=1}^{n} P_{i} \cdot E I_{i}}{\sum_{i=1}^{n} P_{i} \cdot E I_{i, B}}=100 * \frac{E_{t o t}}{\sum_{i=1}^{n} P_{i} \cdot E I_{i, B}}
$$

Where:

$\begin{array}{ll}\mathrm{EII} & =\text { energy intensity index } \\ \mathrm{n} & =\text { number of process steps to be aggregated } \\ \mathrm{EI}_{\mathrm{i}} & =\text { actual energy intensity (EI) of process step } \mathrm{i} \\ \mathrm{EI}_{\mathrm{i}, \mathrm{B}} & \text { = benchmark energy intensity (EI) of process step } \mathrm{i} \\ \mathrm{P}_{\mathrm{i}} & =\text { production quantity for process step } \mathrm{i} \\ \mathrm{E}_{\text {tot }} & =\text { total actual energy consumption for all process steps }\end{array}$

The EII or WII provides an indication of how the actual total production intensity of the winery compares to the benchmark or reference intensity. By definition, a winery that uses the benchmark or reference technology will have an EII or WII of 100. In practice, most wineries will have an EII and WII greater than 100. The gap between actual energy and water intensity at each process step and the reference level energy and water consumption can be viewed as the technical energy-efficiency potential or waterefficiency potential of the winery.

BEST Winery also provides an estimate of the potential for annual energy savings (both for electricity and fuel), energy costs savings, carbon dioxide $\left(\mathrm{CO}_{2}\right)$ emission reduction, water, and water cost savings if the winery would perform at the same performance level as the benchmark or reference winery.

Press continue to see more detailed results, or to continue to evaluate opportunities available for energy and water efficiency in your winery.

\section{Output Summary}

The output summary sheet gives more detailed information about the benchmark winery and the calculations used to determine the EII and WII, as well as the efficiency potentials. It also shows emission factors used to calculate carbon and $\mathrm{CO}_{2}$ emissions reduction potentials.

To continue to evaluate your opportunities for energy and water-efficiency improvement, press the button "Continue". 


\section{Evaluating Efficiency Opportunities}

Once the EEI has been calculated, BEST Winery can be used to preliminary evaluate the potential for energy and water efficiency improvement, by going through a menu of opportunities. The menu is broken into different energy and water uses:

- Energy Efficiency - Refrigeration (EE-Refrigeration)

- Energy Efficiency - Pumps (EE-Pumping)

- Energy Efficiency - Compressed Air (EE-Compressed air)

- Energy Efficiency - Motors (EE-Motors)

- Energy Efficiency - Lighting (EE-Lighting)

- Energy Efficiency - Hot Water and Heat Supply (EE-Hot Water)

- Energy Efficiency - Other Fuels (EE-Other_fuels)

- Energy Efficiency - Other Electric (EE-Other_electric)

- Energy Efficiency - Cogeneration (EE-CHP)

- Water Efficiency (WE - Water)

Each of the sheets contains a menu of efficiency opportunities, including typical energy and/or water savings, capital costs and payback period of that measure. The user needs to specify the share of the total energy and water use used for that specific end-use to which the measure can still be applied, under "potential application".

By right-clicking on the cell with the measure name you can read a brief description of the specific measure. These are also included in this report, in Sections 7 and 8.

The sheet will add the savings of the individual measures and provide a total savings estimate, as well as an average payback period. This information is transferred to the “ASSESSMENT RESULTS” sheet (see below).

In some sheets, e.g., lighting, pumping, motors, the user has the ability to prepare an inventory of all lights, pumps and motors to help estimate the applicable share to which a measure can still be applied or to determine a more detailed estimate of energy use for that specific end use. You do not need to fill in the inventory, but it can help you to improve the estimate of the potential of efficiency improvement. If the inventory tables are not used, BEST Winery determines a typical energy use for that end-use (expressed as energy use per case of wine produced).

After selecting the efficiency measures and opportunities for each end-use, press the button "Continue". This will open the next sheet with efficiency measures. The final "continue" button will open the Assessment Results Worksheet.

\section{Assessment Results}

The Assessment Results sheet provides the final results of the self-assessment of the potential for energy and water efficiency improvement.

The sheet will report the actual EII and WII, as well as what the EII and WII would be after all the selected energy and water-efficiency measures would be implemented. 
It also reports on the technical potential (based on the EII and WII) and cost reductions, as were reported in the "RESULTS" sheet.

The sheet also summarizes the cumulative potential savings of the selected measures. BEST Winery provides an estimate of the annual energy and water savings, annual cost savings, cumulative capital costs, average payback period (of the selected package of measures) and reductions in $\mathrm{CO}_{2}$ emissions.

The saving and cost estimates are based on a survey of the literature and many projects. However, actual savings and costs will vary from project to project. BEST Winery is intended to help you select the most important or cost-effective projects for your winery, and to make a preliminary evaluation of these measures. Only a detailed assessment by a project engineer or a contractor can provide an exact estimate of the savings and costs of your specific project.

Press the button "Continue” to go to the ENERGY_RESULTS Worksheet.

\section{ENERGY_RESULTS and WATER_RESULTS}

BEST Winery provides three tables: 1) electricity measures you've selected; 2) fuel measures you've selected; and 3) water measures you've selected. These three tables contain all the measures that you have selected for each of those three categories, as well as estimated savings, costs and payback periods.

Pressing the "Continue" button on the ENERGY_RESULTS Worksheet will take you to the WATER_RESULTS Worksheet. The Continue button on the WATER_RESULTS Worksheet will take you to the References Worksheet.

\section{References}

The References Worksheet provides all references used in BEST Winery. 


\section{Acknowledgements}

This work was supported by the Food Industry Energy Research (FIER) Grant Program of the Public Interest Energy Research Program (PIER) of the California Energy Commission (CEC), by CEC/CIEE Contract MR-0309 through the U.S. Department of Energy Contract under No. DE-AC03-76SF00098.

Many people inside and outside the industry provided helpful insights in the preparation of the report. First of all, we are grateful to the many people at Fetzer Vineyards in addition to the authors that introduced us the processes that go into industrial winemaking, gave us very good tours of their winery and water treatment facilities, and helped in the development of the tool, including Lee Tolbert, Charles Tolbert, Patrick Doyl, David Murphy and Bob Blue.

We thank Pramod Kulkarni and Rajesh Kapoor of the California Energy Commission and Jatal Mannapperuma of U.C. Davis for their guidance and support. We thank Scott Murtishaw of Lawrence Berkeley National Laboratory for his help with much of the VBA programming in BEST Winery. We thank Doug Scott and Dave Leue of Pacific Gas and Electric Company, Daniel Dettmers of the Industrial Refrigeration Consortium - U.W. Madison, Steve Greenberg of LBNL and Riyaz Papar for technical review and contributions to BEST Winery refrigeration energy measures. We also thank Joe Huang, Hashem Akbari, and Greg Rosenquist of LBNL for their help in modeling several parts of the winery. We thank Matt Atkinson of Benziger Winery and Eric Masanet for their review of the final versions of the tool.

Finally, we thank many people from PG\&E and the Wine Institute for help in publicizing and developing the training workshops for BEST Winery, including Patsy Dugger, Marty Kurtovich, Cheryl Boswell-Barnes, Ann Thrupp and Allison Jordan.

Despite all their efforts, any remaining errors are the responsibility of the authors. The views expressed in this paper do not necessarily reflect those of the California Energy Commission, the U.S. Department of Energy or the U.S. Government. 


\section{References}

AgStar. 2004. AgStar Program. URL: http://www.epa.gov/agstar/

Baen, P. R. and R. E. Barth. (1994). Insulate Heat Tracing Systems Correctly. Chemical Engineering Progress. September: 41-46.

Barnish, T. J., M. R. Muller, and D. J. Kasten (1997). Motor Maintenance: A Survey of Techniques and Results. ACEEE Summer Study on Energy Efficiency in Industry July 8-11, 1997, Saratoga Springs, NY.

Best Practice Programme. (1996a). General Information Report 41: Variable Flow Control. Available for download at http://www.energy-efficiency.gov.uk/index.cfm

Best Practice Programme. (1996b). Good Practice Case Study 300: Energy Savings by Reducing the Size of a Pump Impeller. Available for download at http://www.energyefficiency.gov.uk/index.cfm.

Best Practice Programme. (1998). Good Practice Guide 249: Energy Savings in Industrial Water Pumping Systems. Available for download at http://www.energyefficiency.gov.uk/index.cfm

Black, G. (2002). Above Ground “Caves,” Icons of the California Wine Country. Vineyard \& Winery Management. Jan/Feb: 1-4.

Boulton, R.B., V.L. Singleton, L.F. Bisson and R.E. Kunkee. 1996. Principles and Practices of Winemaking. New York, NY: Chapman \& Hall.

Caffal, C. (1995). Energy Management in Industry. Centre for the Analysis and Dissemination of Demonstrated Energy Technologies (CADDET), the Netherlands. Analyses series 17, December.

California Energy Commission (CEC) and the Office of Industrial Technologies (OIT), Energy Efficiency and Renewable Energy, U. S. Department of Energy. (2002). Case Study: Pump System Controls Upgrade Saves Energy at a Network Equipment Manufacturing Company’s Corporate Campus. January.

California Sustainable Winegrowing Alliance (CSWA) (2004). Wine Community Sustainability Report. Winery Water Conservation and Water Quality: Chapter 10.

California Wineries Mall. 2004. Website: http://www.cawinemall.com/. Accessed July 2004.

Canadian Industry Program for Energy Conservation (CIPEC). (2001). Boilers and Heaters, Improving Energy Efficiency. Natural Resources Canada, Office of Energy Efficiency. August. 
Castellow, C., C. E. Bonnyman, H. G. Peach, J. C. Ghislain, P. A. Noel, M. A. Kurtz, J. Malinowski, and M. Kushler. (c. 1997). Energy Efficiency in Automotive and Steel Plants.

Centre for the Analysis and Dissemination of Demonstrated Energy Technologies (CADDET). (1994). High Efficiency Motors for Fans and Pumps. Case study UK94.502/2B.FO5.

Centre for the Analysis and Dissemination of Demonstrated Energy Technologies (CADDET). (1997a). Saving Energy with Efficient Compressed Air Systems. Maxi Brochure 06.

Centre for the Analysis and Dissemination of Demonstrated Energy Technologies (CADDET). (1997b). Energy Savings with New Industrial Paint Drying and Baking Oven. Case study CA97.504/2X.F06.

Centre for the Analysis and Dissemination of Demonstrated Energy Technologies (CADDET). 2001. Saving Energy with Daylighting Systems. Maxi Brochure 14 (www.caddet.org).

Coggan, M. 2004. Cogeneration at Vineyard 29: Generating Power, and Peace-ofMind, Saving Money and the Environment. Vineyard \& Winery Management 130 (January 2004).

Cole, G. C. (1998). Pharmaceutical Production Facilities: Design and Applications. $2^{\text {nd }}$ Edition. Taylor \& Francis, NY, NY.

Cook, B. 1998. High-efficiency Lighting in Industry and Commercial Buildings. Power Engineering Journal. October: pp.197-206.

Copper Development Association (CDA). (2000). Cummins engine company saves \$200,000 per Year with Energy-Efficient Motors. Case Study A6046.

Copper Development Association (CDA). (2003). Energy Efficiency Case Study: Brass Mill Cuts Costs with NEMA Premium ${ }^{\mathrm{TM}}$ Motors. Available at: http://www.copper.org/applications/electrical/energy/Brass_Mill_Cuts_Cost_A6089.ht $\underline{\mathrm{ml}}$

Dahlberg, E. (2004). Personal written communication with Eric Dahlbert of WineSectets, a manufacturer of electrodialysis equipment. December 6, 2004.

Dettmers, Dan, 2004. Personal communication with Dan Dettmers, Wisconsin Energy Center, November 2004. 
Department of Energy (DOE). (2001a). Office of Industrial Technologies, Energy Efficiency and Renewable Energy. Best Practices Program. Information on steam. http://www.oit.doe.gov/ bestpractices/steam/

Department of Energy (DOE). (2001b). Office of Industrial Technologies, Energy Efficiency and Renewable Energy. Best Practices Program. Information on steam. http://www.oit.doe.gov/ bestpractices/steam/

Department of Water Resources, California. (2004). Water Efficiency Guide for Business Managers and Facility Engineers. October. Available at http://www.owue.water.ca.gov/docs/water_efficiency_guide.pdf

Easton Consultants, Inc. (1995). Strategies to Promote Energy-Efficient Motor Systems in North America's OEM Markets. Stamford, CT.

Efficiency Partnership (EP), (2004a), "Industrial Product Guide - Manufacturing and Processing Equipment: Compressed Air Equipment”, www.fypower.org, http://www.fypower.com/ind/tools/products_results.html?id=100180

Efficiency Partnership (EP), (2004b), "Industrial Product Guide - Manufacturing and Processing Equipment: Motors”, http://www.fypower.com/ind/tools/ products_results.html?id=100201.

Eley, C. and T. M. Tolen, of Eley Associates; J. R. Benya of Luminae Souter Lighting Design; F. Rubinstein and R. Verderber of Lawrence Berkeley Laboratory. 1993. Advanced Lighting Guidelines: 1993. Prepared for the Department of Energy (DOE), California Energy Commission (CEC) and Electric Power Research Institute (EPRI).

Elliot, R.N. (1995). Energy Efficiency in Electric Motor Systems. Washington, DC; American Council for an Energy Efficient Economy.

Environmental Protection Agency (EPA). 2001. Green Lights Program (Part of the ENERGY STAR Program). http://www.epa.gov/Region7/specinit/p2/volprog/estrans.htm

European Environmental Press. (2000). Conservation of Europe’s Water. Mini Guide to European Initiatives. Developed with support from the European Commission's Directorate-General Environment. Available at: http://www.eep.org/miniguides/MINI_ANG/EAU_ENG/an_ea_01-32.pdf. Accessed $4 / 2005$.

Fetters, J.L. 2002. Transformer Efficiency. Energy User News, posted on 4/23/2002. URL: www.energyusernews.com

Fetzer. (2004). Personal communication with various winemakers and operators on winemaking characteristics and energy use and savings. 
Franson, P. (2000). Northwest Wineries Dig Caves, Too: New Technology Addresses Soil and Water Challenges. Wine Business Monthly (May 2000): 43-46.

Ganapathy, V. (1994). Understand Steam Generator Performance. Chemical Engineering Progress. December.

General Motors (GM). (2001). Resource Conservation/Pollution Prevention/Energy Management. General Motors website. http://www.gm.com/company/environment or http://www.gm.com/company/gmability/environment/env_annual_report/ehsreport/htm 1/sec07/content03.htm

Goldstein, L., B. Hedman, G. Knowles, S.I. Freedman, R. Woods and T. Schweizer. 2003. Gas-Fired Distributed Energy Resource Technology Characterizations. National Renewable Energy Laboratory, Boulder, CO (Report NREL/TP-620-34783).

Griffin, B. (2000). The Enbridge Consumers Gas “Steam Saver” Program (“as found” performance and fuel savings projects from audits of 30 steam plants). In: Twentysecond National Industrial Energy Technology Conference Proceedings. Houston, Texas. April 5-6: 203-213.

Hall, L.S. 1999. Pinot Noir Producers go with the Flow, Winemakers Benefit from Using Gravity in Cellar. Wine Business Monthly, September 1999, pp.43-46.

Hovstadius, G. of ITT Fluid Technology Corporation. (2002). Personal communication.

Howe, B. and B. Scales. (1995). Assessing Processes for Compressed Air Efficiency. E Source Tech Update. November.

Hydraulic Institute. (1994). Efficiency Prediction Method for Centrifugal Pumps. Parsippany, NJ.

Hydraulic Institute and Europump. (2001). Pump Life Cycle Costs: A Guide to LCC Analysis for Pumping Systems. Parsippany, NJ.

Hydraulic Institute. (2002). Website, http://www.pumps.org/.

Industrial Assessment Center (IAC). (2001). Industrial Assessment Center Database version 8.1. http://oipea-www.rutgers.edu/database/db_f.html

Ingersoll Rand. (2001). Air Solutions Group-Compressed Air Systems Energy Reduction Basics. http://www.air.ingersoll-rand.com/NEW/pedwards.htm. June 2001.

Jekel, Todd. 2004a. Variable Frequency Drive Opportunities in Industrial Refrigeration Systems, VFD Opportunity I: Condenser Fans. The Cold Front (Vol.4 No. 2), newsletter for the Industrial Refrigeration Consortium at the University of Wisconsin. http://www.irc.wisc.edu, July. 
Jekel, Todd. 2004b. Variable Frequency Drive Opportunities in Industrial Refrigeration Systems, VFD Opportunity II: Screw compressors. The Cold Front (Vol.4 No. 3), newsletter for the Industrial Refrigeration Consortium at the University of Wisconsin http://www.irc.wisc.edu, September.

Jekel, Todd. 2004c. Variable Frequency Drive Opportunities in Industrial Refrigeration Systems, VFD Opportunity III: Evaporator Fans. The Cold Front (Vol.4 No. 4), newsletter for the Industrial Refrigeration Consortium at the University of Wisconsin http://www.irc.wisc.edu, December.

Konopacki, S., H. Akbari, L. Gartland and L. Rainer. (1998). Demonstration of Energy Savings of Cool Roofs. Lawrence Berkeley National Laboratory Report LBNL-40673. Berkeley, CA.

Lawrence Berkeley National Laboratory (LBNL) and Resource Dynamics Corporation. (1998). Improving Compressed Air System Performance, a Sourcebook for Industry. Prepared for the U.S. Department of Energy, Motor Challenge Program.

Lawrence Berkeley National Laboratory (LBNL), Resource Dynamics Corporation and the Hydraulic Institute. (1999). Improving Pumping System Performance: A Sourcebook for Industry. Prepared for the U.S. Department of Energy Motor Challenge Program.

Leue, Dave, 2004. Personal communication with Dave Leue, PG\&E Senior Project Manager, November 2004.

Lighting Research Center (LRC). 2001. Lighting Futures. LEDs: From Indicators to Illuminators? 3(4): http://www.Irc.rpi.edu/Futures/LF-LEDs/index.html

Martin, N., M. Ruth, and L. Price, R. N. Elliott, A. M. Shipley, and J. 2000. Emerging Energy-Efficient Industrial Technologies. Berkeley, CA: Lawrence Berkeley National Laboratory.

National Electrical Manufacturers Association (NEMA). (2001). http://www.nema.org.

National Oceanic and Atmospheric Association (NOAA), 2004. National Climatic Data Center. Available online for various locations: http://www.ncdc.noaa.gov/oa/ncdc.html.

North Carolina Department of Environment and Natural Resources Division of Pollution Prevention and Environmental Assistance (2005). Website: http://www.p2pays.org/

Papar, Riyaz 2004. Personal communication with Riyaz Papar, private energy consultant, November 2004. 
Parekh, P. (2000). Investment Grade Compressed Air System Audit, Analysis and Upgrade. In: Twenty-second National Industrial Energy Technology Conference Proceedings. Houston, Texas. April 5-6: 270-279.

Parker, D. and S. Barkaszi. (1994). Saving Energy with Reflective Roof Coatings. Home Energy Magazine Online. May/June 1994. Available at: http://hem.dis.anl.gov/eehem/94/940509.html. Accessed April 2005.

Phillips, C. 2002. Pump Roundup Wine Business Monthly, September 2002, pp.24-25.

Price, A. and M.H. Ross. (1989). Reducing Industrial Electricity Costs - an Automotive Case Study. The Electricity Journal. July: 40-51.

Quinn, B. 2002. New Technology Slashes Cost and Sludge. Pollution Engineering, February 2002.

Radgen, P. and E. Blaustein (Eds.). (2001). Compressed Air Systems in the European Union, Energy, Emissions, Savings Potential and Policy Actions. Germany.

Roberson, J. A., C. A. Webber, M. C. McWhinney, R. E. Brown, M. J. Pinckard, and J. F. Busch. (2004). After-hours Power Status of Office Equipment and Inventory of Miscellaneous Plug-Load Equipment. Lawrence Berkeley National Laboratory, Berkeley CA. LBNL-53729. Available at: http://enduse.lbl.gov/info/Pubs03_04.html

Scales, B. (2002). Personal written communication.

Scott, Doug, 2004. Personal communication with Doug Scott, PG\&E Consultant, November 2004.

Scott, W. L and W. D. Leech (2004). Wine Caves Beneath the Northern California Vineyards. Tunnel Business Magazine, February 2004.

Southern California Edison (SCE). (2003) "Saving Money with Motors in Pharmaceutical Plants”.

Toyota 2002. Personal communication with Brad Reed, Toyota Motor Manufacturing North America, Inc. May 2002.

Tutterow, V. (1999). Energy Efficiency in Pumping Systems: Experience and Trends in the Pulp and Paper Industry. American Council for an Energy Efficient Economy (ACEEE).

Tutterow, V., D. Casada and A. McKane. (2000). "Profiting from your Pumping System,” In Proceedings of the Pump Users Expo 2000. September. Louisville, KY: Pumps \& Systems Magazine and Randall Publishing Company. 
U. S. Department of Energy, Office of Industrial Technologies (OIT). (2002a). Pumps: Cost Reduction Strategies. Available at the website www.oit.doe.gov/bestpractices.

Vickers, A. (2001). Handbook of Water Use and Conservation. WaterPlow Press: Amherst, MA.

Wine Institute 2002. Sustainable Winegrowing Practices August 2002.

Wine Institute. 2004. Website: http://www.wineinstitute.org/. Accessed July 2004.

Worrell, E., J.W. Bode, J.G. de Beer, 1997. "Energy Efficient Technologies in Industry - Analysing Research and Technology Development Strategies - The 'Atlas' Project", Dept. of Science, Technology \& Society, Utrecht University, Utrecht, the Netherlands.

Xenergy, Inc. (1998). United States Industrial Electric Motor Systems Market Opportunities Assessment. U.S. Department of Energy's Office of Industrial Technology and Oak Ridge National Laboratory. Massachusetts.

Zeitz, Ronald A. ed. 1997. CIBO Energy Efficiency Handbook. Council of Industrial Boiler Owners, Burke, Virginia. 